C00--623--181

\title{
SOLID STATE PHYSICS PROGRAM
}

\section{A CAPACITIVE HIGH PRESSURE GAUGE: PART II APPARATUS AND RECENT MODIFICATIONS}

C. ANDEEN, J. FONTANELLA AND D. SCHUELE

U. S. ATOMIC ENERGY COMMISSION CONTRACT NO. AT 11-1.623 TECHNICAL REPORT N0. 77 NOVEMBER, 1972
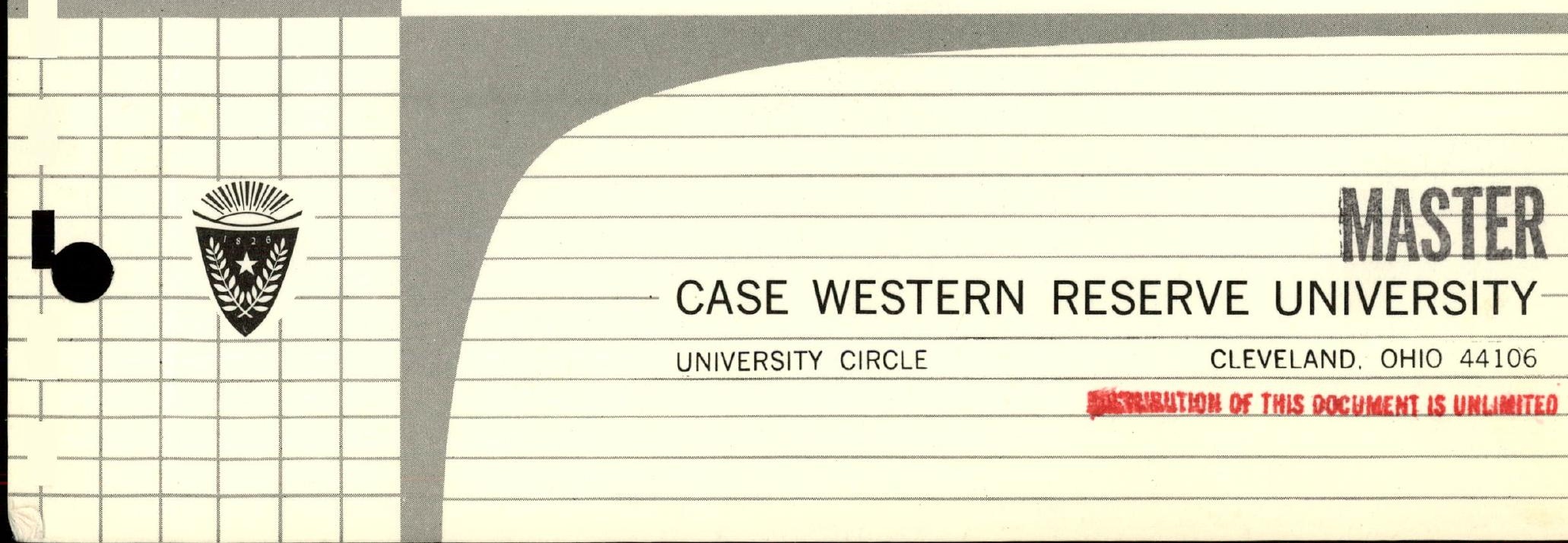

CASE WESTERN RESERVE UNIVERSITY 


\section{DISCLAIMER}

This report was prepared as an account of work sponsored by an agency of the United States Government. Neither the United States Government nor any agency Thereof, nor any of their employees, makes any warranty, express or implied, or assumes any legal liability or responsibility for the accuracy, completeness, or usefulness of any information, apparatus, product, or process disclosed, or represents that its use would not infringe privately owned rights. Reference herein to any specific commercial product, process, or service by trade name, trademark, manufacturer, or otherwise does not necessarily constitute or imply its endorsement, recommendation, or favoring by the United States Government or any agency thereof. The views and opinions of authors expressed herein do not necessarily state or reflect those of the United States Government or any agency thereof. 


\section{DISCLAIMER}

Portions of this document may be illegible in electronic image products. Images are produced from the best available original document. 
$600-623-181$

A CAPACITIVE HIGH PRESSURE GAUGE: PART II

APPARATUS AND RECENT MODIFICATIONS

Carl Andeen, John Fontanella, and Donald Schuele

ABSTRACT

In previous reports (AEC Technical Report \#63 [000-623-150], Rev. Sci. Instr. 42, 495 [1971]) a cepacitive gauge for the accurate measurement of high pressures was presented. In that paper, only the basic idea and the results of a prototype gauge were given. In another report (AEC Technical Report \#73[000-623-169]) the details of sample preparation and a basic description of the electronics rere included. In the present paper, details of the apparatus and further comments on the electronics are presented along with recent modifications which increase the practicality of such a gauge.
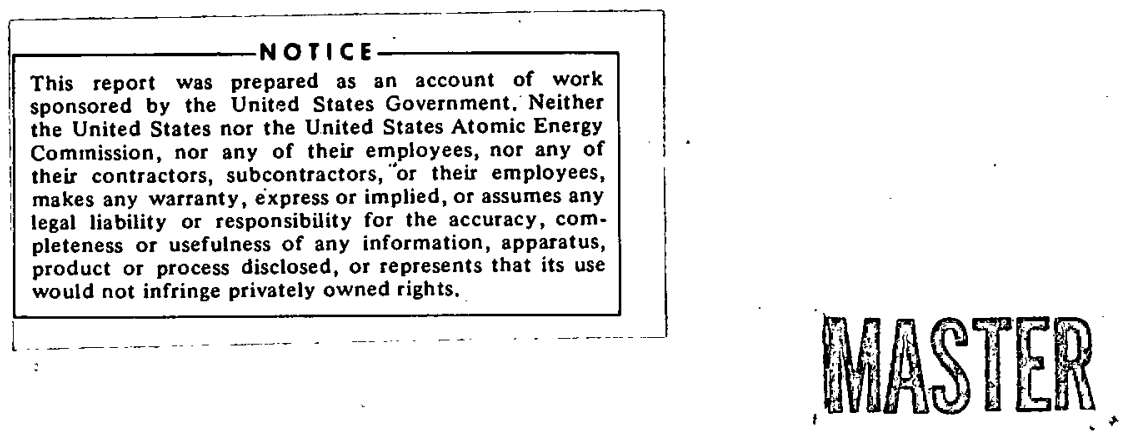


\section{INTRODUCTION}

The capacitive pressure gauge is basically a device which measures hydrostatic pressure by detecting the change in the direct capacitance of a suitably fabricated three-terminal capacitor which is immersed in the pressure fluid. The prototype gauge $1,2,3$ utilized a disc of single crystal $\mathrm{CaF}_{2}$ as the pressure sensing element. Three electrodes were deposited onto this disc by the evaporation of aluminum films through suitable masks to form a three-terminal capacitor. The completed sensor was inserted into a multiple sample holder contained in a temperature controlled high pressure vessel and its three-terminal capacitance was compared with that of a similar disc of $\mathrm{CaF}_{2}$ contained in a separate temperature controlled chamber which was at atmospheric pressure.

In a calibration at the National Bureau of Standards in July of 1970 the ratio of the three-terminal capacitance of eight separate pressurized sensors prepared as above to that of a reference sensor was measured with a specially constructed capacitance bridge and every sensor was found to obey the same relation of the form $C / C_{0}=I-A P+B^{2}$ to within the accuracy of the dead weight gauge against which they were calibrated.

Even though the initial results are very encouraging, the gauge as discussed here and in AEC Technical Reports No's 63 and 73 has several requirements which in practice are quite difficult to satisfy. CaF 2 , which was chosen as the most promising sensor material at the time the prototype gauge was developed, has a temperature coefficient of 
capecitance of $\sim 250 \mathrm{ppm}$ per ${ }^{\circ} \mathrm{C}$, and a pressure coefficient of capacitance of $\sim 1 / 4$ ppm per psi. These figures point out several problems in the capacitive gauge which mist be solved in order for it to become an acceptable pressure gauge.

First, since the change in capacitance due to a $1^{\circ} \mathrm{C}$ temperature change is equivalent to that due to a pressure change of 1000 psi it is necessary that the temperature of the pressure vessel be controlled to better than one millidegree if a gauge stability of one psi is desired. Alternatively, the reference sensor can be thermally attached to the pressure vessel to achieve some cancellation of the rather large temperature effect. Drawings are included in this report for a pressure vessel, designed for the pressure range of 0 to 45,000 psi, which contains two independent pressure sensors; with a reference capacitor chamber (also containing two independent sensors, but at atmospheric pressure) attached directly to the pressure vessel.

Second, since the capacitance change due to one psi is only one part in four million it places severe requirements on the capacitance bridge used for measuring the ratio of the capacitance of the pressurized sensor to that of the reference capacitor. Since no comercial capacitance bridge is acceptable for this purpose a limited range capacitance bridge was designed and constructed especially for use with the capacitive pressure gauge. This capacitance bridge has recently been modified to simplify its use and improve its performance. Schematics for this modified limited range capacitance bridge are included in this report. 
Also, since the capacitance changes due to pressure are so small it is imperative that the three-terminal capacitance of the sensor be as well defined as possible, which requires careful attention to the details of sample geometry, electrode geometry and deposition, and complete shielding of the sensor and its associated electrical leads from stray capacitance and other anomalous effects. These last several topics have been covered sufficiently in the previous reports that not much will be said about them in this report.

Finaliy, even though the present report describes a thermally compensated capacitive pressure gauge which uses $\mathrm{CaF}_{2}$ as the pressure sensor, and the resulting. gauge does work quite well for measurements where sufficient time is allowed for the attainment of temperature equilibrium, it is still limited by the large temperature coefficient of $\mathrm{CaF}_{2}$ which requires very close approach to final thermal equilibrium and also necessitates careful design of the temperature bath in which the pressure vessel and attached reference chamber are immersed.

Obviously, a material having a lower temperature coefficient than $\mathrm{CaF}_{2}$ would be desirable. A search is continuing both at Case Western Reserve University and at the National Bureau of Standards to find a better sensor material from the standpoint of temperature stability requirements for a given pressure sensitivity. To date no naterial has been found which is significantly better than $\mathrm{CaF}_{2}$ in this respect, and even if a material were found which has a zero temperature coefficient of capacitance, other factor's such as reproducibility between samples, hysteresis upon pressure cycling, and compatibility with the 
pressurizing fluid must also be taken into account. It appears then that $\mathrm{CaF}_{2}$, in spite of the difficulty introduced by its large temperature coefficient, can still be considered as the best choice for a capacitive pressure gauge sensor, and the present report is an attempt to achieve a reasonably straight-forward working gauge using $\mathrm{CaF}_{2}$ as the pressure-sensor. However, it should be mentioned that even if at a future date a better material is found for the sensor, the basic apparatus remains unchanged. 
PRESSURE VESSEL AND TEMPERATURE CONTROL

In the prototype gauge the pressure sensors were contained in a pressure vessel which was pbysically separate from the reference capacitor enclosure. This prototype gauge was designed to obtain a sensitivity and hopefully a stability of $1 / 5 \mathrm{psi}$, which therefore required a temperature control on both the pressure vessel and the reference capacitor enclosure of better than $1 / 5$ millidegree. Since thịs was to be a dynamic system some means had to be provided for dissipating the heat associated with increasing the pressure in the pressure vessel. This could have been achieved rather easily by immersing the pressure vessel in a controlled temperature oil bath which would automatically remove the excess heat and retain temperature equilibrium. Unfortunately it is quite difficult in a circulating oil bath to obtain a temperature stability of $1 / 5$ miliidegree. With a circulating water bath this degree of temperature control could be achieved more easily due to the lower viscosity, higher thermal conductivity, and higher specific heat of water, all of which reduce the tendency to form significant temperature gradients. Ob.viously, the water would have to be in a closed system or covered with a thin layer of oil to prevent cooling by evaporation. However, in our case the presence of water, or even ethylene glycol which takes up a significant amount of vater from the atmosphere, is unacceptable because of 
its effect on the very critical electrical measurements which must be made and the adverse effect of water on the pressure sensors.

As an alternative to a liquid temperature bath the prototype . pressure vessel was heated directly by eighteen thermal conduction type power resistors distributed uniformly over the surface of a one cm. thick aluminum thermal jacket which surrounded the maraging steel pressure vessel in which the pressure sensors were contained. A glass encapsulated thermistor was inserted in a V-groove machined on the inside of the aluminum thermal jacket so that the thermistor was in thermal contact with the pressure vessel. The pressure vessel was isolated from the ambient temperature by surrounding it with a temperature controlled enclosure which was kept at a temperature a few degrees lower than the desired temperature of the pressure vessel. The difference in temperature between the enclosure and the pressure vessel was adjusted so that the quiescent power supplied to the pressure vessel (which was always kept at $\sim 35^{\circ} \mathrm{C}$ ) was approximately one watt. This one watt quiessent power was sufficient to allow quite rapid return to the set point after a pressure increase. With full scale power adjusted to two watts the pressure vessel responded fust as quickly to a decrease in pressure.

The temperature control for the enclosure was quite simple since it required a stability of only $0.01{ }^{\circ} \mathrm{C}$. The temperature control for the pressure véssel however was of the proportional, rate, and reset type and was capable of controlling to $0.0001^{\circ} \mathrm{C}$. However, since the 
temperature sensors in all of the temperature controls were glass encapsulated thermistors there were short term temperature hysteresis effects after opening the enclosure and allowing the pressure vessel to lose its set point. When the pressure vessel was allowed to fall to room temperature it would take $\sim 24$ hours to return to within one millidegree of the set point, so reasonable care was taken to prevent large temperature variations in the pressure vessel.

The temperature control for the reference capacitors was basically the same as the temperature control for the pressure vessel except that the reference capacitors (which were contained in a doubly isolated copper chamber) could be left for long periods at their set point (which also was $\sim 35^{\circ} \mathrm{C}$ ), thus avoiaing problems with the associated thermistors.

As a check on the final prototype setup the pressure vessel was vented to atmospheric pressure and the ratio of the capacitance of the enclosed pressure sensor to that of the reference sensor was monitored with the specielly constructed sapacitance bridge whose output was observed on a chart recorder. The ambient temperature was increased from $25^{\circ} \mathrm{C}$ to $\sim 28^{\circ} \mathrm{C}$ with several space heaters and was allowed to. remain at $28^{\circ} \mathrm{C}$ for $\sim$ one hour. The temperature of the room was then lowered to $\sim 20^{\circ} \mathrm{C}$ with a large air conditioner and was allowed to sit for $i$ one hour, with the capacitance ratio being monitored continuously. At no time during the several hour run did the capacitance ratio vary by more than one part in $40,000,000$. This corresponds to a 
temperature control of the pressure vessel to better than $0.0001{ }^{\circ} \mathrm{C}$, a temperature control of the reference capacitor oven to better than $0.0001{ }^{\circ} \mathrm{C}$ and a stability of the capacitance bridge to better than one part in 40,000,000 over the entire ambient temperature range from $20^{\circ} \mathrm{C}$ to $28^{\circ} \mathrm{C}$.

Since the prototype gauge was originally developed for studying the pressure coefficient of the dielectric constant of many different materials, including several which are rather hygroscopic; and the pressure vessel had to be opened each time new samples were inserted, it was a distinct advantage to be able to avoid immersing the pressure vessel in an oil bath for control of its temperature. (An oil bath which is exposed to the atmosphere will inevitably pick up a small amount of water contamination from the surrounding air, and there was a chance of affecting the dielectric properties of the hygroscopic crystals by contact with contaminated oil.) This consideration more than offset the added complication of separate temperature controls for the pressure vessel and reference sensor enclosure.

A capacitive pressure gauge intencied only for the accurate measurement of pressure, however, would not be adversely affected by a slight degree of water contamination in the oil bath, provided that the sensor material is non-hygroscopic. Fortunately CaF , which performed remarkably well in the prototype gauge, is sufficiently nonhygroscopic that a design for a thermally compensated gauge in which the reference sensors are immersed rectly in the oil bath is quite 
practical. In this design the reference capacitors are enclosed in a block of aluminum which is bolted directly to the bottom of the pres- sure vessel. The drawings for this modified pressure vessel-reference enclosure are included and explained briefly in the following pages. 
Drawing - 1 Pressure Vessel

The pressure vessel for the prototype gauge was machined out of maraging steel, this material being chosen largely because of the smal]. dimensional change which occurs upon heat treating, thus minimizing problems occurring with machining tolerances. However, in maraging steel forgings of this size there is a possibility of seams occurring. which can cause premature failure of the pressure vessel at surprisingly low pressures. Evidently this problem is much less important in 4340 steel, and therefore this type of steel is specified in the present design. However, for 4340 steel the dimensional change upon heat treating is larger and more unpredictable.

The actual dimersions of the pressure vessel are dictated by the desired pressure range $(0-45,000 \mathrm{psi})$ and by the rather large diameter of the $\mathrm{CaF}_{2}$ pressure sensors ( 2 one inch). The dimensions shown. in the drawing also allow for a relatively large safety factor, which is important when working with high pressures.

The pressure vessel has two pressure ports as well as the main closure plug opening. These two side ports (which mate with standard 1./4" diameter high pressure tubing fittings) allow for convenient bleeaing of the pressure fiuid to remove any air bubbles.

The $1 / 32 "$ radius at the three inside corners (which should also be free of tool chatter marks) is to prevent excessive stress concentration at these corners. The $7 / 64 "$ pressure ducts enter the pressure 
chamber 1/4" from the bottom for the same reason (to avoid stress concentration). The three $1 / 8^{\prime \prime}$ weep holes prevent any pressure buildup under the main closure collar or $1 / 4 "$ tubing.collars in the event of a leak at trese locations. The remainder of the details for the pressure vessel are either" self-explanatory or will be covered later, but it is probably worth repeating here that a generous amount of material should be left for finish machining because of the unpredictable behavior of 4340 steel upon heat treating. 


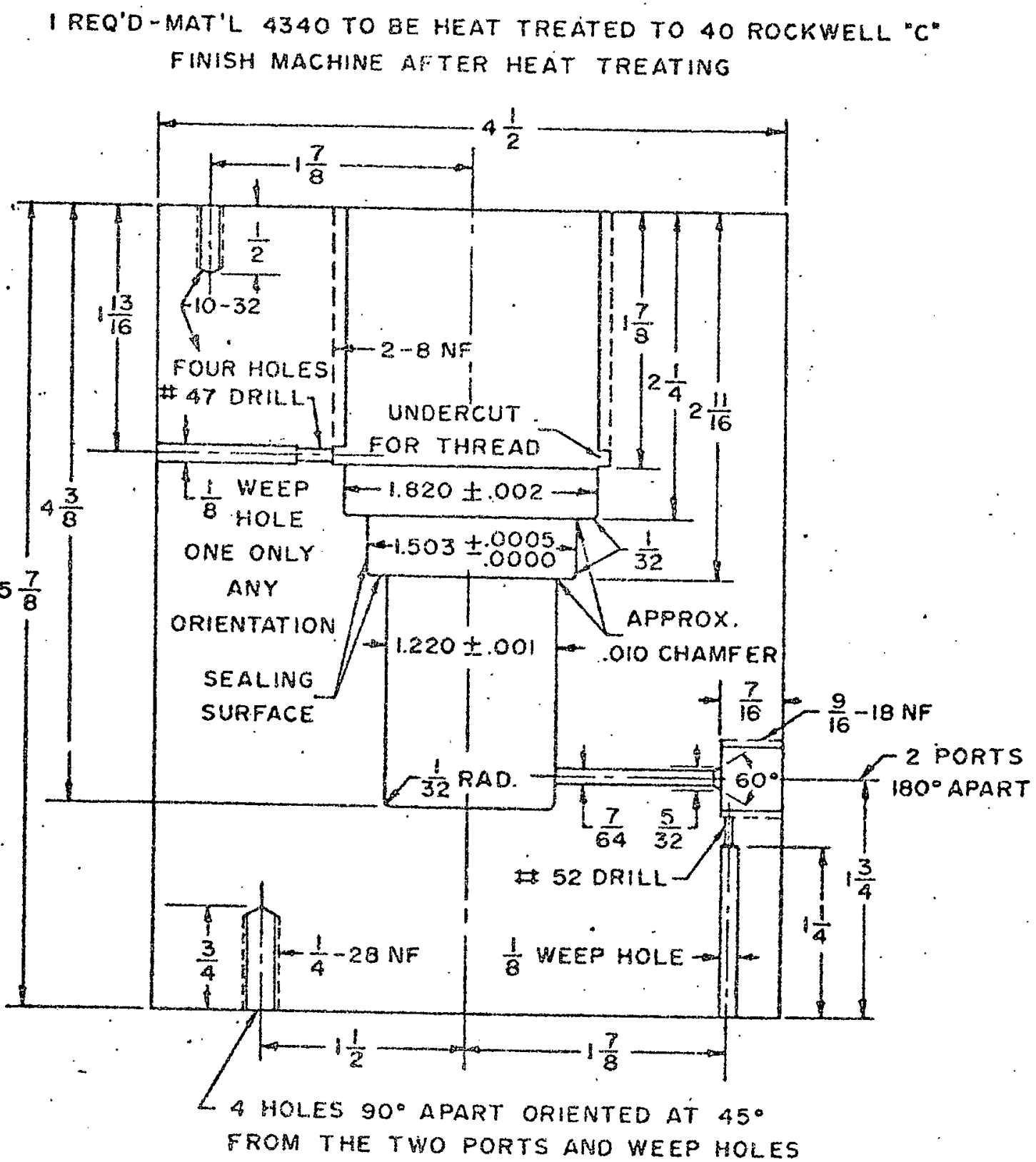

ALIGN $\frac{1}{4}-28$ HOLES IN LINE WITH $10-32$ HOLES AT TOP

ORAWING - I

- PRESSURE VESSEL for capacitive pREsSURE gaUge 


\section{Drawing - 2 Reference Capacitor Cell}

The reference sample holder contains two independent reference capacitors (for redundancy in case of failure of one of the reference sensors). One reference sensor is mounted on each side of the aluminum block and each reference sensor is held in place by one of the brass reference electrode holders.

The completed reference capacitor holdex is designed to be bolted to the bottom of the pressure vessel using four 1/4" - 28 Allen cap screws. Electrical connections are made to the sample electrodes by routing small dianeter teflon coated wires through suitably drilled holes which connect to brass shim stock electrodes mounted on phenolic backing plates as described in AEC Technical Report No. 73 . Each "high" electrode is mounted on a one inch diameter backing plate which is inserted into the large recess, while each "low" electrode is mounted on a $1 / 2^{\prime \prime}$ diameter backing plate which is inserted into the small recess in the brass aover. The electrical connecting wires terminate on the outside at four BNC type UG-1094/U connectors which ifit into the $3 / 8^{\prime \prime}-32$ tapped holes. The perpendicularly drilled $3 / 8^{\prime \prime}$ holes are for access to the terminals for making the electrical connections, and when the reference capacitor cell is mounted on the pressure vessel these holes are closed off, thus preventing any stray capacitance effects between adjacent terminals. When soldering the electrical connections to the BNC fittings it is helpful to leave some excess 
wire which can be coiled up in each $3 / 8^{\prime \prime}$ well so that the electrode holders can be removed from the reference cspacitor cell without unsoldering the terminals each tine this is done.

An important detail should be mentioned here. The bore in the reference capacitor cell is $1.065^{\prime \prime}$ while the corresponding diameter of the reference "low" electrode holder is only 1.020". This difference leaves room for a $1 / 4 " \times 3-1 / 8^{\prime \prime}$ strip of teflon $i 20$ mils thick which serves as a liner in the cell to reduce the possibility of electrical shorting of the "high" electrode to ground. This teflon liner also improves the botudary conditions of the reference sensor, making it less dependent on the electrical characteristics of the temperature bath oil which will eventually leak into the interior of the reference cell. Since the inner circumference is $\sim 3-1 / 4^{\prime \prime}$ the $3-1 / 8^{\prime \prime}$ strip leaves a gap of $n 1 / 8^{\prime \prime}$ which must be positioned where the "high" electrical lead passes through the aluminum wall. of more importance is the location of the "Iow" electrical lead as it passes through the brass cap. This lead must not be allowed to "see" the teflon strip because of the large stray direct capacitance which would result. The "low" electrical lead must be routed approximately as shown in the "note!" detail.

The 10-32 tapped holes in the reference capacitor holder, as vell as the 10-32 tapped holes in the top of the pressure vessel, are for attaching phenolic mounting plates which serve the dual purpose of insulating the reference capacitor chamber against rapid temperature 
Pluctuations and also allow the pressure vessel to be placed in a horizontal position, spaced as desired from the bottom of the temperature control bath without any direct thermal contact to the bottom of the tank. With the pressure vessel horizontal and raised in this manner the oil can flow both above and below it, thereby hopefully improving the temperature stability of the system.

In the event that the temperature bath undergoes rapid temperature fluctuations it would actually be a djadvantage to thermally couple the pressure vessel to the oil bath in this manner. For this case it would be preferable to wrap the pressure vessel and attached reference cell in an insulating blanket berore immersion in the oil. This would increase the equilibrium time slightly, but would significantly reduce the temperature variation between the reference celI and the internal sample chamber since the reduction in the heat flow rate would reduce the thermal gradients in the pressure vessel. 
TO BE BOLTED TO BOTTOM OF PRESSURE VESSEL FOR THERMAL CONTACT
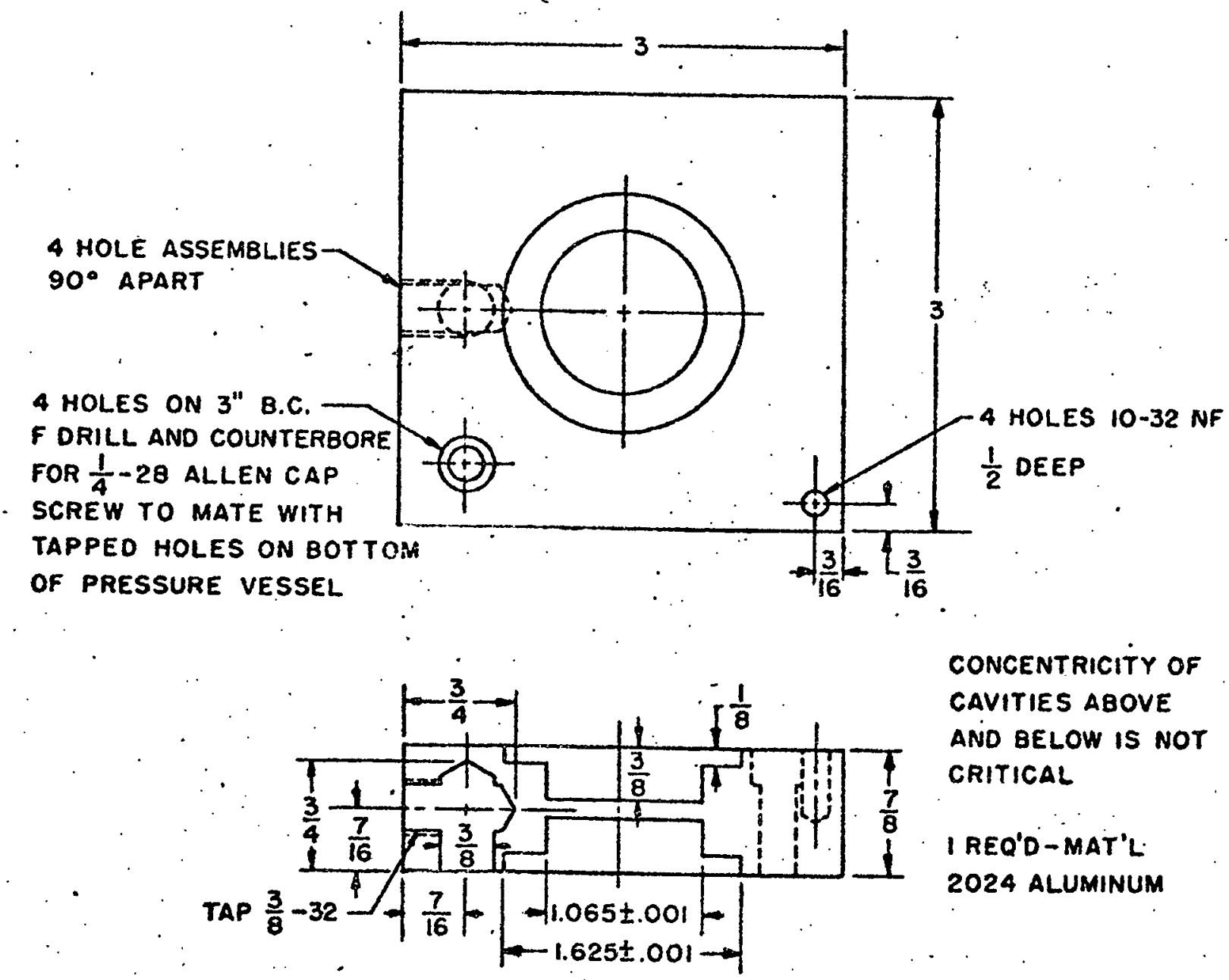

REFERENCE CAPACITOR CELL FOR CAPACITIVE FRESSURE GAUGE

MAT'L - BRASS

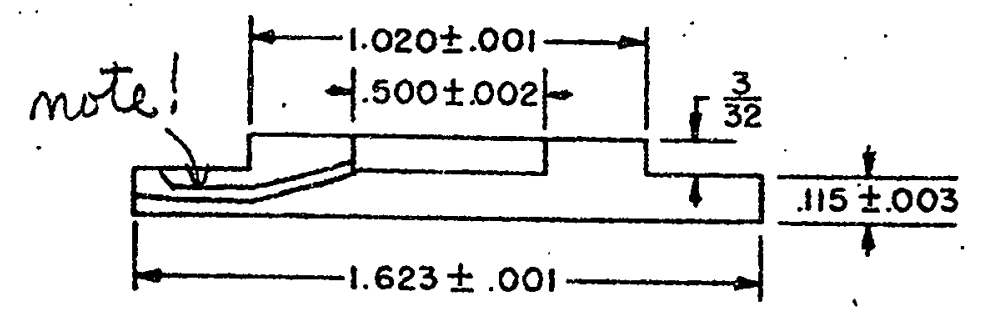

REFERENCE ELECTRODE HOLDER' FOR CAPACITIVE PRESSURE GAUGE DRAWING - 2 


\section{Drawing - 3 Closure Plug Collar}

The closure plug collar mates with the $2^{\prime \prime}-8$ thread in the top of the pressure vessel. The wrench flats on this collar allow th to be tightened to prestress the o-ring pressure seal. Here again the material is 4340 steel and the previous comments should be noted. 


\section{REQ'D MAT'L 4340}

TO BE HEAT TREATED TO 40 ROCKWELL " $\mathrm{C}$ "

FINISH MACHINE AFTER HEAT TREATING

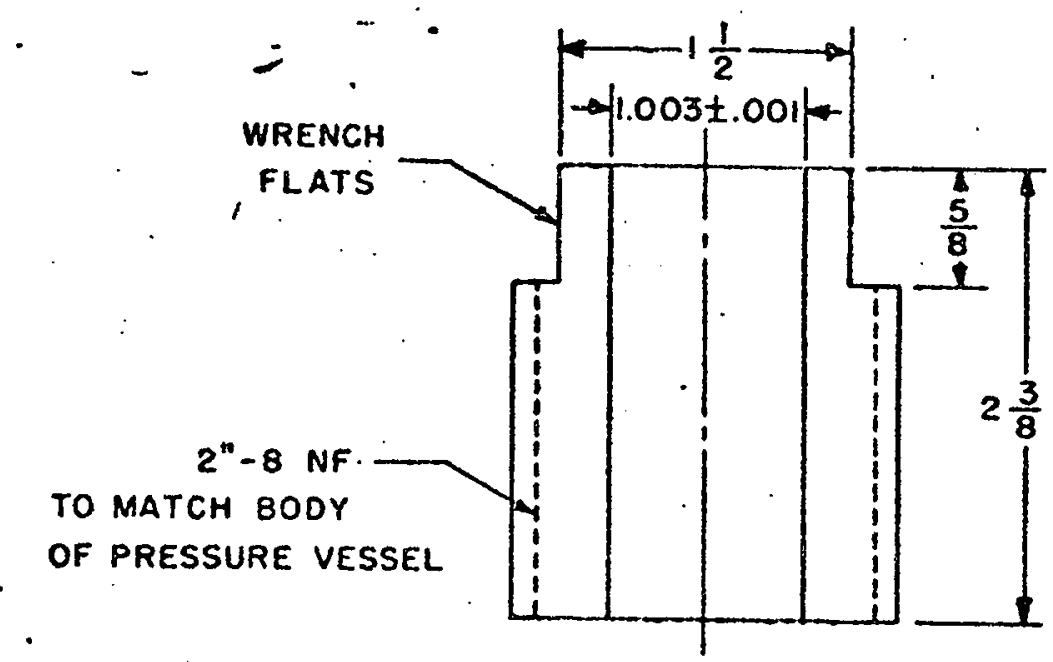

CLOSURE PLUG COLLAR FOR CAPACITIVE PRESSURE GAUGE

DRAWING - 3 


\section{Drawing - 4 Electrical Assembly}

This drawing shows the completed assembly of the electrically connected sample holders whose connecting wires pass through the closure plug and terminate at the upper terminal block. Obviously when the electrical connections are complete the closure plug collar shown in Drawing 3 would have to be included on the stem of the closure plug. The closure plug collar was omitted for clarity. 


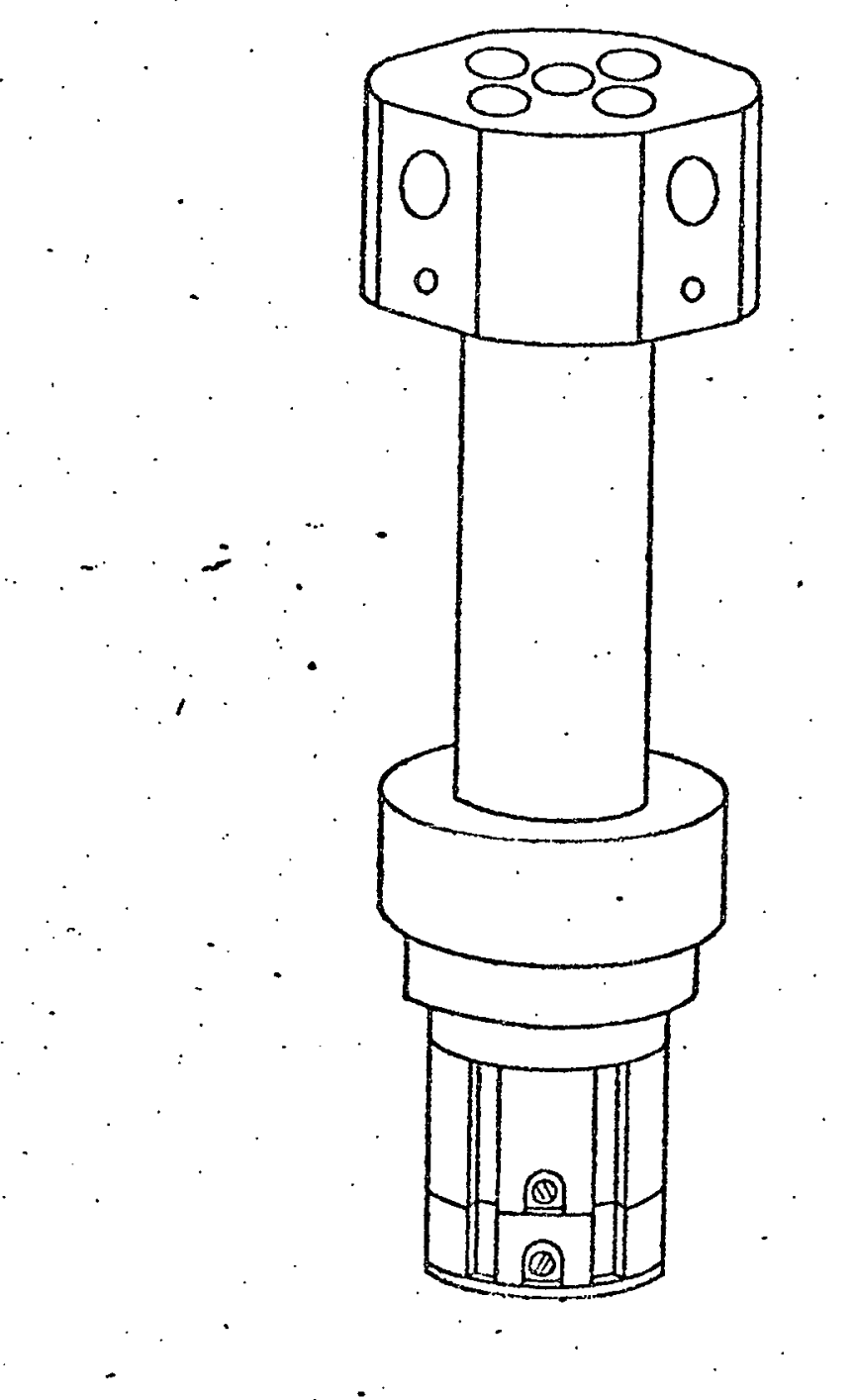

TERMINAL 8LOCK, CLOSURE PLUG, AND SAMPLE HOLDER ASSEMBLY FOR CAPACITIVE PRESSURE GAUGE!

DRAWING - 4 


\section{Drawing - 5 Terminal'Block}

The terminal block is in many respects similar to the reference capacitor cell of prawing 2. The electrical leads from the sample holders uItimately pass up through the $3 / 16^{\prime \prime}$ holes in the bottom of the terminal block and are connected to BNC type UG-1094/U connectors. The $3 / 8^{\prime \prime}$ hole is again an access hole but in the terminal block only enough excess electrical lead shouid be left to allow the lead to remain slack. After soldering the electrical leads to the BNC connectors the $3 / 8^{\prime \prime}$ holes should be closed up with $3 / 8^{\prime \prime}$ snap plugs to prevent any stray capacitance. However, before connecting any electrical leads, four 3/4" lengths of at least $20 \mathrm{mil}$ wall 3/16" O.D. stainless steel tubing should be inserted in the $3 / 16^{\prime \prime}$ holes in the bottom of the terminal block. These pieces of tubing should match the mating closure plug and are meant to prevent shearing of the electrical leads in the event that the terminal block is rotated relative to the closure plug. These short tubes can be held in place in the terminal block with $6-32$ set screws. It is mandatory that these tubes be used, without them the electrical leads would almost certainly be sheared off. 


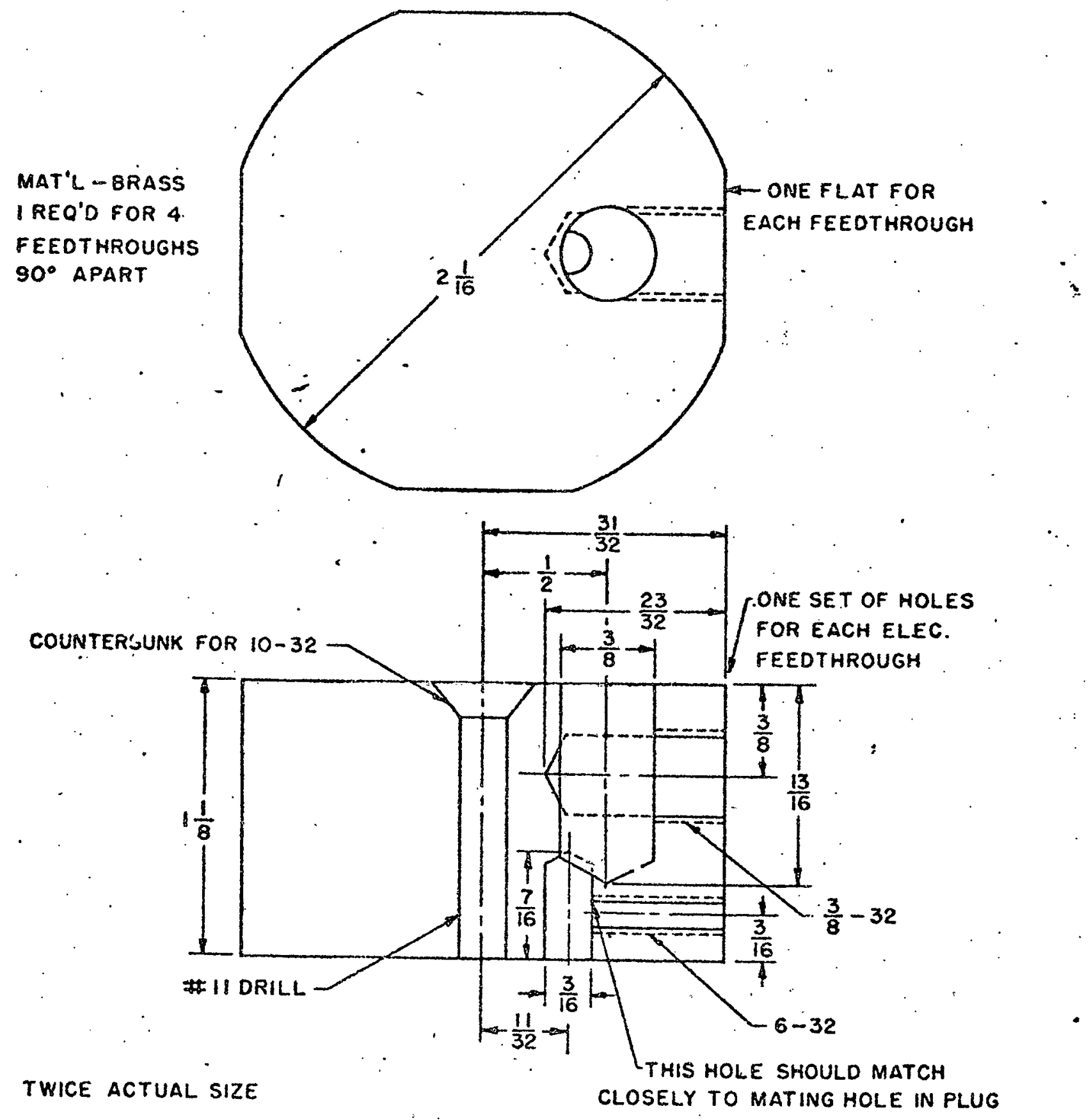

TERMINAL BLOCK FOR CAPACITIVE P GAUGE

DRAWING - 5 
Drawing - 6 closure Plug and Feedthrough Electrodes

The closure plug has two important functions. It seals the pressurized internal chamber, and allows the electrical connections to pass from the high pressure region inside of the sample chamber to atmospheric pressure through electrically insulated high pressure conical feedthroughs.

The pressure seal is made by using a \#17-218 O-ring which is a . teflon 0-ring with a nominal I.D. of $1-1 / 4^{\prime \prime}$ and a nominal $0 . D$. of 1-1/2". In the prototype gauge no trouble has been experienced from outward extrusion of this O-ring at high pressures, but if this becomes a problem an anti-extrusion ring could be added if necessary. In the prototype gauge the dimension labeled $1.217^{\prime \prime}$ was originally $1.215^{\prime \prime}$ which resulted in a radial gap of $\sim 2-1 / 2$ mils between the closure plug and the sample chamber bore of the pressure vessel. This gep in the prototype gauge was sufficient to allow inward extmusion of the teflon 0-ring upon tightening the closure plug collar. An antiextrusion ring was therefore used at the inside corner of the O-ring, which seems rather backward. This problem should not be significant after changing the $1.215^{\prime \prime}$ dimension to $1.217^{\prime \prime}$ since this reduces the radial gap from $2-1 / 2$ mils to $1-1 / 2$ mils.

The conical high pressure electrical feedthroughs, are rather time consuming to make but are quite reliable in use if made correctly. After machining the conical electrodes they should be checked against the conical wells in the closure plug to be sure that the $\sim 16^{\circ}$ 
included angle is the same for both. If the fit is good and no rocking is observed the \#65 drilled hole in the tip of the conical electrode should be tinned with solder using a suitable flux and the tinned end of a six inch length of the insulated center conductor of RG-174/U coaxial cable should be soldered into the end of the cone. A reasonable force should then be applied to the wire to check the solder joint. If extreme difficulty is encountered in obtaining a good solder joint the conical plugs could be made from beryilium copper rod (heattreated after machining), to make the soldering easier, but in general this should not be necessary.

The conical surface of the electrodes should then be thoroughly cleaned of all solder and flux, and the electrodes should be covered with aluminum oxide filled (white) epoxd, making sure that there is a sufficient thickness of epoxy and that there are no air gaps at the conical surface. The importance of thoroughly mixing the two components of the epoxy cannot be overemphasized, because a small inclusion of an unmixed portion will almost certainly cause the coating to fail during machining. The epoxy can be applied to the cones with a wooden coffee stirring stick and by rubbing a very thin initial layer onto the conical surface it is easy to "wet" the entire surface to make sure no air gaps are present. The epoxy layer can then be built up as desired, and after setting somewhat the epoxy can be teased with ary fingers to obtain the desired contour. The epoxy should then be allowed to set thoroughly. 
After hardening, the electrode can be chucked in a collet and the epoxy removed up to the rear edge of the cone, making sure that the cutting tool does not take too cieep a cut as this might chip the epoxy. Since the white epoxy has an aluminum oxide filler this will rapidly dull the cutting edge of the tool, which should therefore be checked and resharperied quite often. Once the epaxy is removed up to the rear edge of the cone it is only necessary to. slowly remove the epoxy on the conical surfaces until the diameter at the rear edge is $\sim 16 \mathrm{mils}$ larger than the diameter of the uncoated electrode (corresponding to an epoxy thickness of $\sim 8 \mathrm{mils}$ ). Care should be taken to maintain the correct included angle $\left(\sim .16^{\circ}\right)$ in order to obtain a good fit into the conical wells in the closure plug. Care should also be taken when machining the epoxy near the small end of the cone (where the wire comes out), because it is easy to chip the epoxy at this point and this could lead to catastrophic failure of the epoxy coating or an even worse failure in case the electrical lead is torn off by being caught in a chuink of epoxy. To minimize the probability of this type of failure, relatively little epaxy should be applied beyond the small end of the cone, and the exposed length of wire should be inserted into a short length of tubing held in the tailstock chuck to prevent its whipping around during the machining. After completing the machining operation it is important to check that the electrodes have a good solid feel in their mating wells.

To complete the electrical feedthroughs they are very lightly coated with clear epoxy which has been allowed to set until it has become 
somewhat tacky. Then, after thoroughly cleaning the conical wells with acetone and allowing them to dry completely, the conical electrodes are inserted into the wells and are lightly tapped into place with a small hamer. If a significant excess of clear epoxy is visible in the 1/4" diaxaeter region of the conical well it should be removed with a pipe cleaner: After tapping the feedthroughs into place and waiting until the epoxy on the mixing board has become quite viscous the feedthroughs can be given a final tap and then the pressure vessel should be closed of 1 . with the teflon 0 -ring inserted and pumped up to $\sim$ 10,000-20,000 psi to set the feedthrough. The pressure should then be reduced to a few thousand psi until the epoxy on the mixing board becomes like chewing gum. At this time the pressure vessel should be pumped up to $\sim 20,000$ psi and left at this pressure until the epoxy hardens.

If no leak occurs the electrical feedthrough assemblies are complete. However, if a leak does occur and if it is obvious which feedthrough is at foult, the feedthrough should be removed by inverting the closure plug and filling the well with acetone (being careful not to contaminate the adjacent ieedthroughs). After a period of time it should be possible to rernove the bad feedthrough by working it out by twisting the exposed stem with a pair of pliers. To avoid scarring the stem it is helpful to slide a short length of metal tubing over the stem while it is being squeezed with the pliers. Obviously the well should be thoroughly cleaned before inserting enother feedthrough. 
Once again the material is 4340 steel, but the only critical machining dimension on the closure plug is the $1.502^{\prime \prime}$ dimension which - determines the clearance betweer: the closure plug and pressure vessel and therefore determines the tendency for outward extrusion of the teflon 0-ring. The points marked sealing surface should be free of tool marks since they provide the high pressure seal. The four \#10 drilled holes at the top of the closure plug should be checked for mating with the ends of the short pieces of $3 / 16^{\prime \prime}$ tubing extending from the terminal block. This should be done before seating the electrical feedthroughs, since these holes could be enlarged if necessary.

When the electrical feedthroughs have been seeted successfully, and have been tested to operating pressure $(\sim 45,000$ psi) or above without any leaks being found, and the feedthroughs show infinite resistance to ground at all pressures, the closure plug, closure plug collar, and terminal block can be assembled. The four electrical leads extending up from the closure plug should be passed through the $3 / 16^{\prime \prime}$ tubes and out through the top of the terminal block, and the terminal block should be temporarily attached to the closure plug with a flat-head or oval-head $1-1 / a^{\prime \prime} \times 10-32$ machine screw. The BNC fittings should be inserted into the terminal block (using lockwashers to prevent loosening of the BNC fittings during later use) and the leads can then be trimmed to their desired length. After separating the terminal block and closure plug a small amount of insulation can be removed from the ends of these electrical lesois. The closure plug (with the closure plug collar attached) can now be permanently fastened to the terminal 
block and the electrical leads can be soldered to the BNC fittings, after which the access holes should be closed off with $3 / 8^{\prime \prime}$ snap plugs. This completes the closure plug assembly except for the sample holders, which will be electrically connected to the above assembly by sliding split tubing over the exposed stems of the electrical feedthroughs. 


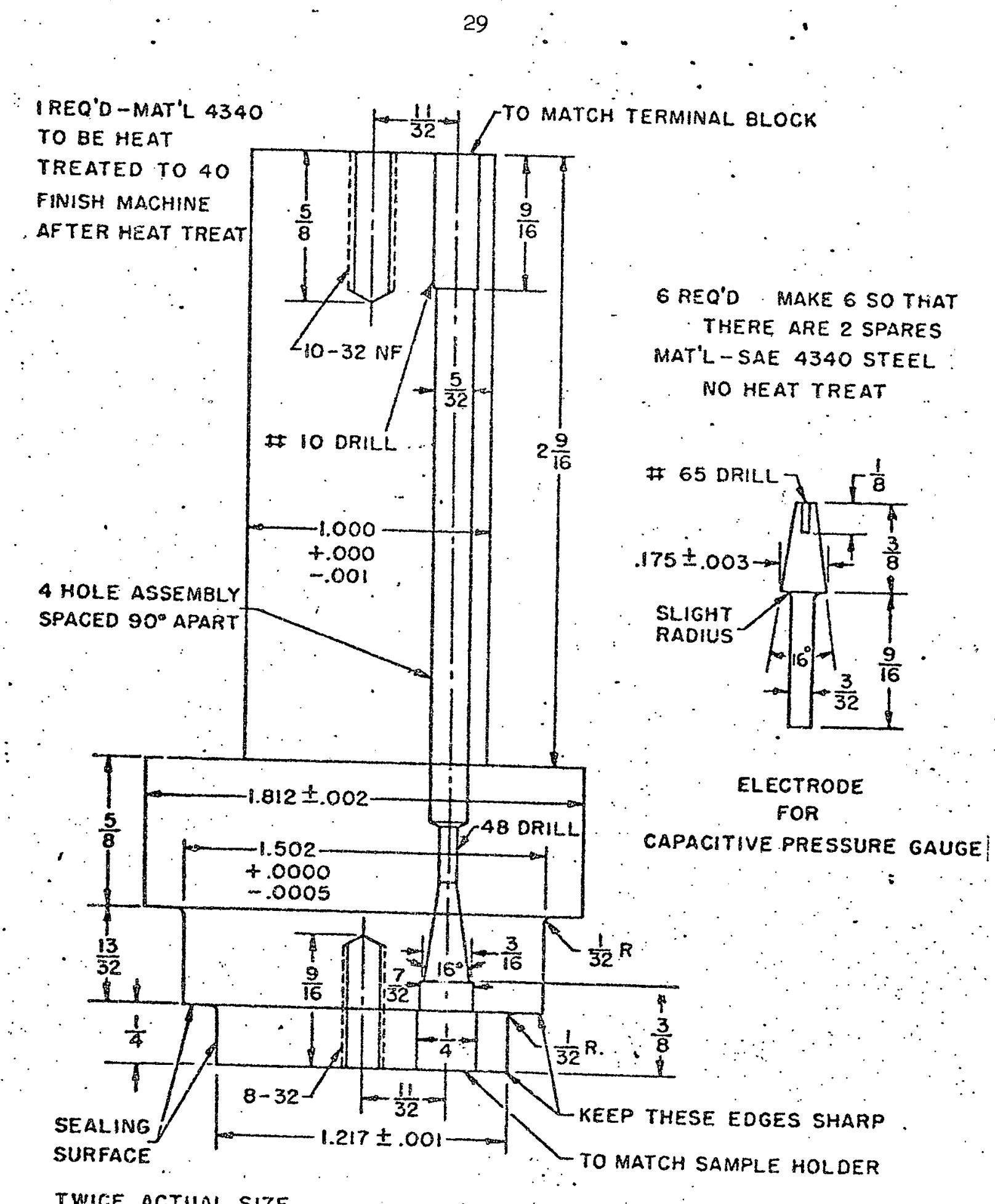

IREQ'O-MAT'L 4340
TO BE HEAT

TREATED TO 40

FINISH MACHINE 


\section{Drawing - 7 Sample Holders}

- The prototype gauge was originally designed with the capability of containing five samples simultaneously. This required a minimum of six electricel feedthroughs in the closure plug. Initially the five sample holders were electrically connected so that all of the "high" electrodes were common and the "low" electrode of the desired sample could be selected with a selector switch, the "Iow" electrodes of the four remaining samples being grounded. With this connection the AC bridge voltage is continuously applied to all of the samples, thus aroiding possible short term effects (e.g., seif heating, such as occurs in resistors) which might occur if the bridge voltage were applied only seconds before making the capacitance measurement. It was subsequently determined that this effect was negligible at the level. of the present measurements, which therefore allowed more flexibility in the arrangement of the electrical connections.

The sample holder wiring was changed from a miniature pin and plug arrangement to permariently attached viring and was modified to allow two parallel independent configurations, each comprising two samples having a common "low" lead and separate "high" leads. This arrangement (which used only four of the sample compartments, the fifth being filled with a dumm plug) was much easier to use since it was permanently wirea in with small diameter teflon covered wires which removed the tedious pin and plug connections. The samples were simply 
inserted into the sample holder cups to form a stack which, before attaching the brass closure cap, was shielded by a thin sleeve of 4 mil brass shim stock which held the electrical leads in their milled slots. This wiring arrangement was used for the calibration of the eight samples of $\mathrm{CaF}_{2}$ (four at a time) at the National Bureau of Standards. The sample holder was later modified to ellow one sample (using two electrical feedthroughs) to be used as a pressure sensor, while three other samples (using a common "Iow" electrical feedthrough and three separate "high" electrical feedthroughs) were inserted in the remaining sample holders to investigate the pressure variation of their dielectric properties. The results of these investigations hove been written up in several later reports. $4,5,6,7,8$

The prototype gauge with a closure plug assembly containing only one sample (a calibrated $\mathrm{CaF}_{2}$ sensor) has also been used quite successfully as a pressure gauge by one of our colleagues in the Department of Chemistry at Case Western Reserve University in studying the effect of pressure on the conductivity of solutions. 9

The sample holder cups, including details of the electrode-backing plate, sample, serrated ring, electrode-becking plate sandwich, have been described previously in AEC Tech. Rep. 73.

To provide redundency (in the event of sample failure, or failure of one of the electrical feedthroughs), the present design calis for a three part sample holder containing two samples which are electrically connected so as to be totally independent, thus requiring four electrical feedthroughs, two for each sample. 
The prototype apperatus containing the five sample holders was shielded by a sleeve of brass shim stock, the main purpose of which was to contain the electrical leads in their proper grooves. A single sample holder wes also used in the prototype apparatus. Since this sample holder was quite short and had only two grooves, a different method cf" electrical lead containment was used. Two short pieces of brass shim stock were bent into the shape of a channel and inserted into the two milled grooves. These shields vere held in place by the spring tension of their sides against the walls of the grooves (the amount of tension being adjusted by bending as desired), and were carefully inserted into the grooves to avoid cutting the insulation on the electrical leads by the sharp edges of the shim stock. This type.

- of electrical lead containment and shielding is used in the presently described sample holder. The electrical leads are routed from the phenolic-backed electrodes through the brass sample holders to the milled grooves using the same guidelines as those described for assembling the reference capacitor cell. These electrical leads are connected to the exposed stems on the closure plug. The leads are soldered to $I / 4^{\prime \prime}$ lengths of $I / 8^{\prime \prime} O . D^{\circ}, . . / 64^{\prime \prime}$ wall brass tubing which has been cut down the side with a copir 3 s\&w and deformed slightly by squeezing so that good electrical contac; is made when the split sleeve is pushed onto the stem of the electrical feedthrough. A sufficient length of electricel lead should be used to allow the sample holder cups to be separated easily, but not so much that the shielding channel is difficult 
to insert properly over the wire when the wire is folded over in its groove to take up the slack after the sample holder is assembled.

Shearing of the leads between the closure plug and terminal block was prevented by the short lengths of thick walled $3 / 16^{\prime \prime}$ tubing through which the electrical leads passed. The same shearing possibility exists between the closure plug and sample holder and is prevented by $3 / 8^{\prime \prime}$ lengths of $\sim 10 \mathrm{mil}$ wall stainless steel tubing which has been sawed twice or milled to leave a $I / 8^{\prime \prime}$ wide lengthwise gap in the side of the tubing through which the electrical lead will pass (this gap is obviously oriented toward the outside wall of the sample holder). The leads pass through notches which are filed or sawed in the narrow, area where the $1 / 4^{\prime \prime}$ arilled hole is adjacent to a milled groove. Care should be taken to remove all burrs or sharp edges fram the short lengths of split tubing and from the notches or other access holes through which the electrical leads will pass. As an added precaution against electrical shorting or failure of th: electrical connections by flexing, short lengths $\left(\sim 3 / 8^{\prime \prime}\right)$ of $\sim 3 / 16^{\prime} 0.0$. teflon tubing which has been cut down the side can be insertel between the $1 / 8^{\prime \prime}$ sleeve over the stem and the 1/4" O.D. stainiess steel tube. By correctly orienting the lead relative to its solder joint and wrepping the lead once around the sleeve before passing it through the slots in the teflon and stainless tubes the prob:bility of failure due to flexing or pulling will be greatly reduced.

The completed sample holder does not extend to the bottom of the chamber in the pressure vessel. In the five sampie holder of the prototype gauge, which was surrounded by a sleeve of brass shim stock, great 
care vas taken to orient a fairly large hole in the sleeve so as to be adjacent to the pressure inlet duct. This was done so that upon reducing the pressure in the versel the sleeve could not be punched into the duct by the outward flow of oil, and required a rather large positioning pin and keyway so that the closure plug was oriented properly each time the closure plug collar was tightened. This positioning pin was inserted through a hole in the pressure vessel which increased the stress it a critical location, and has not been used in the present design. However, since the orientation of the milled grooves with their retaining channels, which are rather thin, is now arbitrary, a similar punchturough possibility exists. To prevent this from happening, the bottom of the assembled sample holder extends only as far down into the pressure vessel as the $7 / 64$ " pressure ducts, and consequently punching cannot occur. It has already been mentioned that this $7 / 64 "$ hole enters the pressure chamber $\sim 1 / 4$ " from the bottom to avoid stress concentration, and hence there is an $21 / 4$ " deep empty volume at the bottom of the pressure chamber after the sample holder is inserted. This empty volume is undesirable because it increases the volume of oil in tie sample chanber. Since oil is very compressible compared with the other materials in the sample chamber most of the work that is done in increasing the pressure in the pressure vessel goes into heating of the cil, and the greater the volume of oil in the sample chamber the larger the temperature risie will be for a given pressure increase. One of the biggest limitations in the capacitive pressure gauge is the effect of temperature on the $\mathrm{CaF}_{2}$ 
sensors, and therefore every effort has been made to minimize the volume of recesses in the sample holder (since these will be filled with oil upon pressurizing the system). To minimize the empty volume in the bottom of the sample holder $81.215^{\prime \prime}$ O.D. disc of aluminum with a chamer of $\sim 40 \mathrm{mils}$ on both faces, and threaded 6-32 to allow easy insertion and removal, should be inserted into the bottom of the sample chamber. The required thickness, which depends upon the particular pressure vessel, can be determined by inserting a wad of lead fojl ( 24 mil) or soft aluminum foil into the bottom of the sample chamber. Then, with the sample holder attached and with an O-ring pressure seal in place the closure plug collar should be securely tightened. After opening the pressure vessel the thickness of the squashed foil will be an indication of the required disc thickness. The actual disc should be made $\sim 15$ mils thinner than indicated to allow for variation in o-ring sizes, tightening torque, and to avoid the possibility of "bottoming out" the sample holder. It is probably worthwhile to check the final clearance by aroppirg a smell piece of aluminum foil into the chamber on top of the disc. This aluminum foil should not be totally flattened upon tightening the closure plug and is a good measure of the final clearance. 


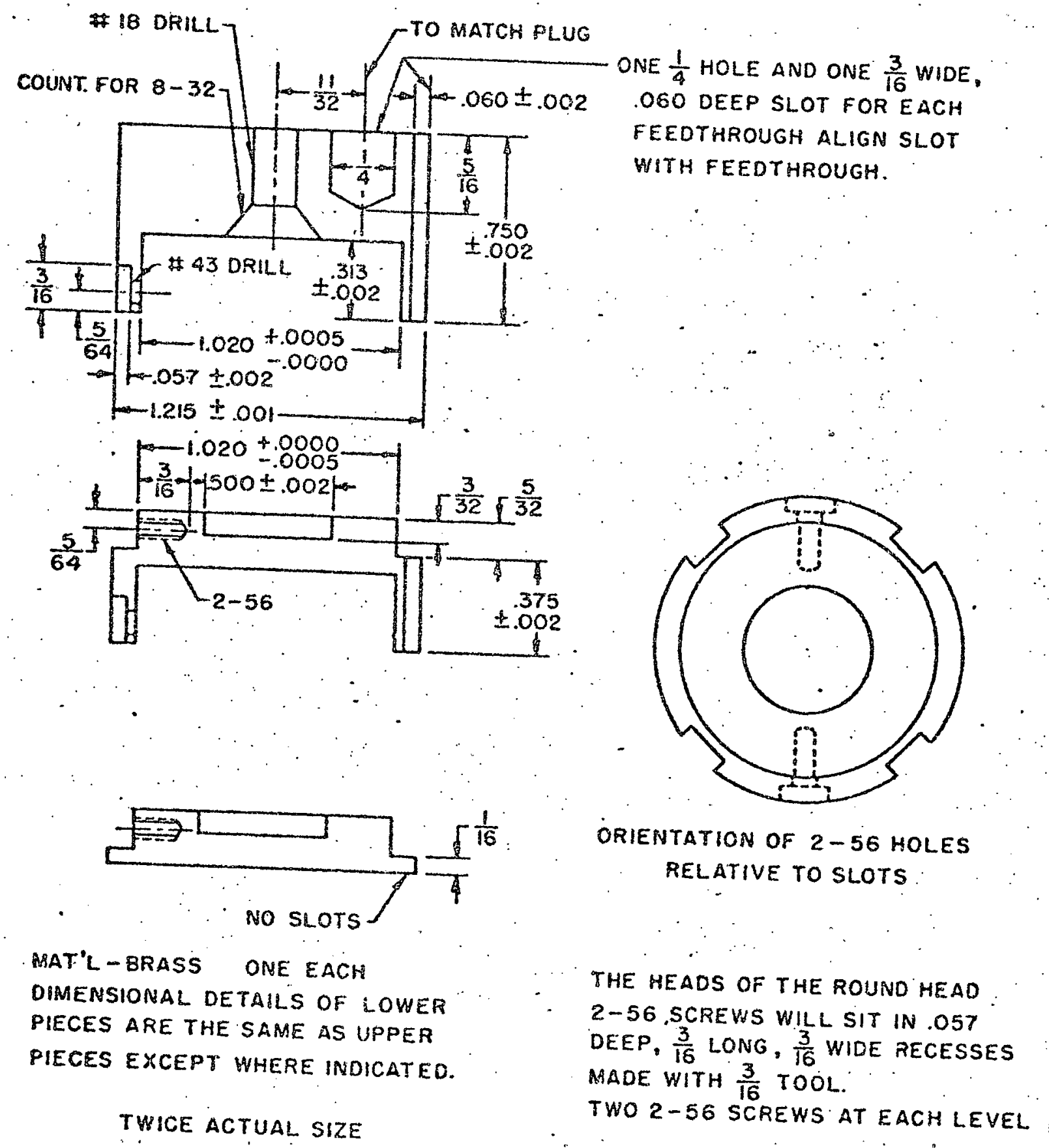

SAMPLE HOLDERS FOR CAPACITIVE PRESSURE! GAUGE

DRAWING -7 


\section{CAPACITANCE BRIDGE}

The capacitance bridge which was used in the prototype apparatus has been described briefly in AEC Tech. Rep. 73. This capacitance bridge was derigned to be used only for accurately measuring the capacitance ratio between two three-terminal capacitors, each having a nominal capacitance of up to several hundred picofarads, and with a capactance ratio bewtween $4 / 5$ and $5 / 4$. Since the capacitance of both the pressure sensor and the reference sensor was $\sim 6 \mathrm{pF}$ and it was desired to measure their capacitance ratio to one part in 20,000,000 (corresponding to $1 / 5 \mathrm{psi}$ ) great care was taken to obtain the necessary ratio accuracy and to bbtain sufficient sensitivity to observe the correspondingly very small changes in capacitance.

The basic componerits of the prototype capacitance bridge consisted of (I) a crystal controlied oscillator, (2) a limited-range, specially wired ratio transformer, (3) a tuned input, high impedance, low noise FET preamplifier, (4) a two stage tuned amplifier, and (5) a dual channel lock-in amplifier for detecting the in phase and quadrature un- balance signals.

The crystal controlled oscillator was necessary because of the high $Q(\sim 70)$ of the tuned circuit at the input to the preamplifier, which resulted in relatively large phase angle changes for small changes in the oscillator frequency. The input tuning is also a disadvantage when switching from one sample to another having a separate "low" connection (as in the present setup, in which all of the electrical 
connections are totally independent for redundancy in case of failure) becouse the input tuning capecitor must be readjusted to correct for differences in cable.or input cnpacitance. Even the small changes in the lead capacitances and sample capacitance. which occur upon pressurizing the sample chamber cause slight changes in the input tuning, and the tuning is even more annoying in an oil bath system in which capiliary action of the oil can vary the capacitance in the cables and-feedthrough wiring.

The present capacitance bridge was designed to have an untuned input, which removes the necessity of crystal controlling the oscillator, and also reduces the thermal noise contributed by the tuned input circuit. Removing the input tuning inductor has the added advantage of making the bridge less susceptible to pickup from stray magnetic fields, which is particularly troublesome when using large values of inductance, even when the inductor is carefully shielded. However, by not tuning out the reactance of the shunt capacitance of the cables and wiring the resultant input impedance at the detector is much lower, aithough almost purely capacitive (which introduces very little thermal noise), and consequently the input signel voltage for a given pressure change is much smaller than in the prototype design. The preamplifier stage is therefore more critical with respect to noise introduced by the input transistor and its associated circuityy, but has actually been improved noise-wise over the prototype circuit, and is capable of resolving pressure changes of approximately 1/20 psi (even at a pressure of 45,000 psi), although for this to be meaningful the temperature 
control and the ratio transformer would have to be improved somewhat, and also the present sensors are not quite good enough to justify this resolution.

The remainder of the circuitry in the prototype gauge is basically unchanged, although the method of excitation of the divider transformers in the ratio transformer divider has been improved to simplify the "trimming" procedure which is used to obtain the required. accuracy.

The schematics for the various sections of the modified capacitance bridge are presented on the following pages, and will be described in some detail. However, an attempt to duplicate this bridge is not suggested unless the reader is thoroughly fumiliar with the subtleties associated with the construction of high-accuracy ratio trensformer dividers, low signal level wiring layout and detection, and lock-in amplifiers.

If more detailed information about this bridge is desired it would be preferable to contact the authors directly, since any attempt. at duplication of this bridge will almost certainly lead to a repetition of mistakes which have probably already been made by the authors in the construction of several capacitance bridges similar to the one presented here. 
Schematic - 1 Power Supply

The power supply is designed to deliver nominally regulated +15 volts and -15 volts to the operational amplifiers (all of which are metal-cased 709 C's), +2h volts and -24 rolts to drive the buffer amplifier which isolates the oscillator from the loading due to the ratio trensformer, and a reasonably long time constant, filtered and regulated +20 volts for the preamplifier.

The \pm 15 volts are obtained from simple series-pass transistors with a 15 volt Zener diode as a reference. The 68 ohm resistors are current limiting resistors which, together with the lN914's prevent burning out the operational amplifjers in case of a short in a seriespess transistor.

The $1000 \mathrm{mfd}-50$ volt electrolytic capacitor reduces the 120 cycle ripple by a factor of five and also improves the regulation of the power supply, even though it may seem redundant.

The +20 volt supply uses a $2 N 2222$ transistor as a series-pass transistor and is filtered to reduce the effect of line transients by mears of the $10 K-47 \mathrm{mfd}$ combination (one-half second time constant) at its base. However, the +20 rolt suppiy has not been tested sufficiently to consider the present design as being final. 


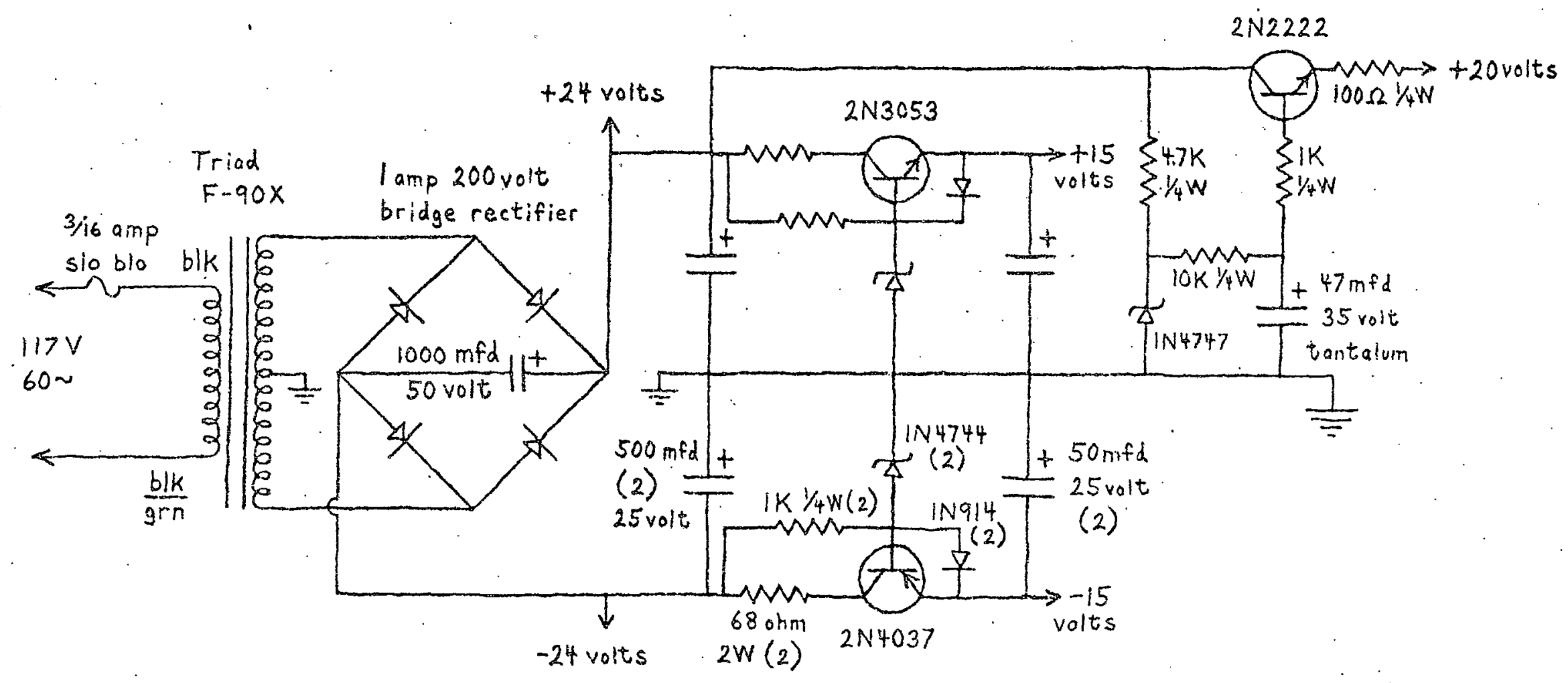

Schematic-1 Power Supply for Capacitive Pressure Gauge 


\section{- Schematic - 2 Oscillator}

A feedback circuit of the type shown in Schematic - 2 will oscillate stably at a frequency where the phase shift is zero degrees and the overall gain is one. To achieve the $0^{\circ}$ phase shift a parallel resonant circuit, combining a 2.8 Henry inductor and a $2200 \mathrm{pF}$ zero temperature coefficient cspacitor, is used to oscillate at $\sim 2 \mathrm{kHz}$. Fine control of this frequency is achieved by varying the $2.5 \mathrm{~K}$ variable resistor (which is shursted by $2.027 \mathrm{mfd}$ capacitor for stability). This fine control of the frequency allows the phase shift through the tuned amplifier portion of the bridge to be varied slightly in a well controlled manner.

To achieve unity gain; which is important to obtain an undistorted output, a peak detector is used to compare the output signal level with the voltage across a zener diode, with the resultant output being used to vary the channel resistance of an FEP to adjust the overall gain to unity.

A complementary symetry buffer amplifier is usea to isolate the oscillator from the load to minimize distortion. The quiescent current in the buffer is adjusted by the series string of $10 \mathrm{~K}-430 \mathrm{ohm}$ resistors and by the value of the emitter resistors (10 ohms). When driving the ratio transformer divider, which is isolated from the buffer amplifier by a low capacitance isolation transformer, the distortion in the output of the divider is less than $1 \%$, and is free of spurious effects. 
In preliminary tests of this oscillator it was not damaged by shorting its output, and always returned to its original frequency and amplitude after disabling it. Also, in tests where the line voltage was reduced with a Variac until the oscillator became unstable it always returned to: normal upon increasing the line voltage.

In another test where the frequency of this oscillator was adjusted to zero beat with the crystal-controlled prototype oscillatior the frequency remained within one part in several thousand over the entire week of the test. 


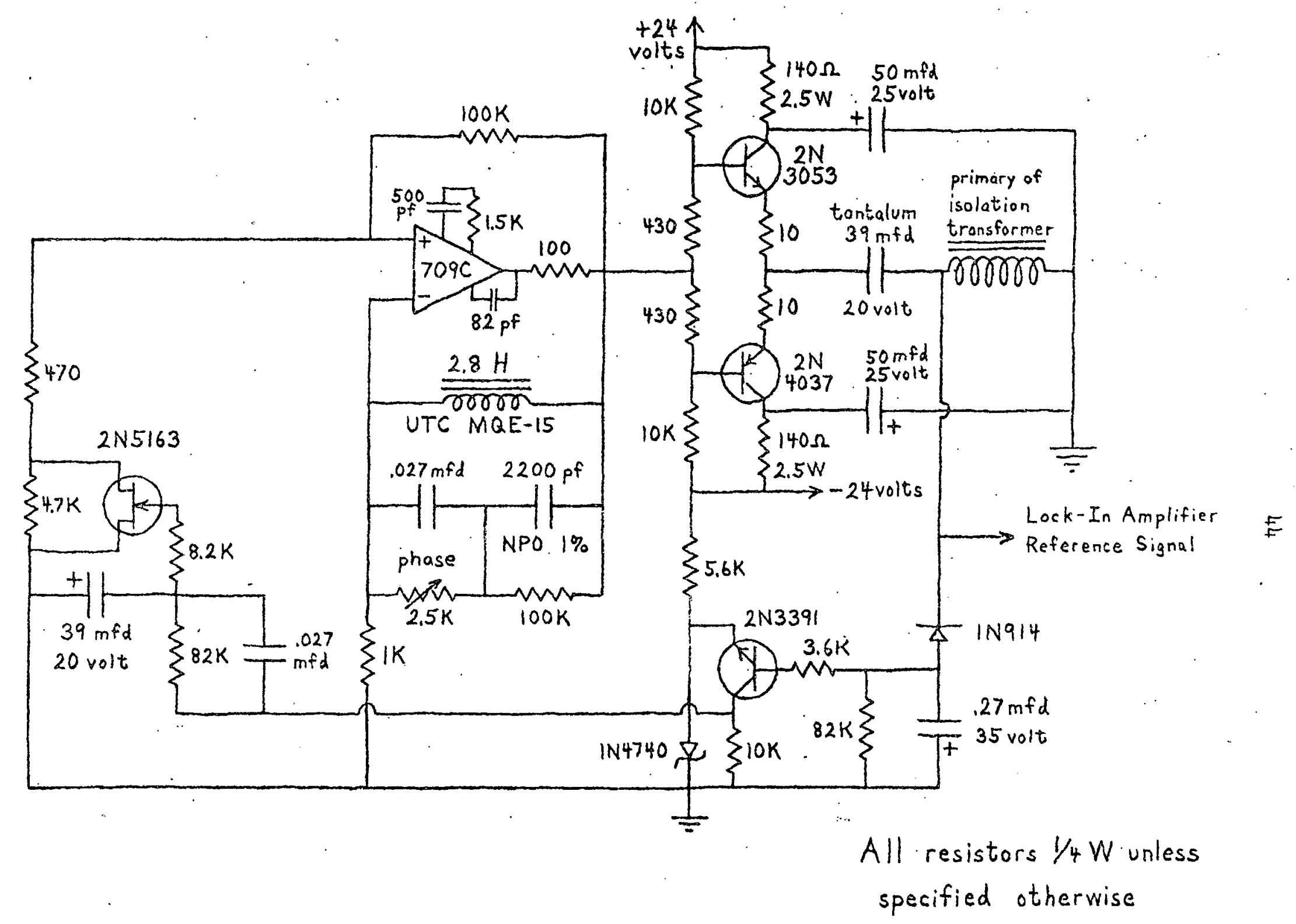

Schematic-2 Oscillator for Capacitive Pressure Gauge 


\section{Schematic - 3 Ratio Transformer Divider}

The ratio transformer divider consists of eight cascaded divider transformers, the first of which is an unswitched nine section divider transformer, followed by seven switchable decade divider transformers. The first divider transformer is indirectly driven from a multiple winding isolation transformer and is insulated by polyethylene foam insulation to minimize the capacitance between its coupling loop and the other isolation transformer windings. This isolation is necessary to reduce the unbalancing effect of any capacitance between the coupling loop and windings which are not part of the "floating" voltage divider. The isolation transformer also allows several voltages to be obtained for other functions. These will be described later.

The electroiytic coupling capacitor between the output of the oscillator and the primary of the isolation transformer is for the purpose of preventing any DC current from flowing in the primary winding of the isolation transformer since this could saturate its core, resulting in distortion or excessive loading of the oscillator.

In the prototype ratio transformer core " $O$ " was' a ferrite core which was wound with four groups of 14 wires each (2 of which were used as the primary, 4 were connected in series between steps 0 and 4,4 were connected in parallel between steps 4 and 5 , and 4 were connected in series between steps 5 and 9). Each group was wrapped around the core 30 times and the four groups of wires ( 56 wires) were connected 
together in four parallel sets as described. The resulting distributed capacitarice was quite large and was one of the main limitations of the prototype bridge since this resulted in a quadrature error between steps 4 and 5 as compared with one-fourth of the voltage between steps $0-4$ or $5-9$.

In the present design several changes have been made. Core " 0 " is now a Permalloy tape wound core having a higher maximum Plux density than that for ferrite resulting in fewer turns being required for a given design voltage (even with a smaller core area). To avoid anomalous effects due to DC magnetization of the Permalloy core it is operated quite close to magnetic saturation so that it is continuously being demagnetized. The primary of transformer " $O$ " is wound separately by winding two parallel wires around the core in a right hand direction until the inner circumference is filled. One of these two wires is then unwound and replaced by another wire lying in the gap along the inner circumference of the core, but wound in a left hand direction which requires this second winding to cross over the first winding on the outside circumference of the core. After making sure that the number of turns is identical these two vindings are connected in parallel, with the right hand and left hand windings canceling the "net turn" effect. The secondary is then wound onto transformer " 0 " by first cutting 12 equal length strands of wire and twisting them together quite tightly with an electric drill, after which the resulting bundle is closewound around the core until the inner circunference is filled. The wires are then connected as before ( 4 wires in series from steps 
$0-4,4$ wires in parallel from steps $4-5$, and 4 wires in series from steps 5-9), there being a total of only 12 wires. Since there now is very little wire in the secondary winding the distributed capacitance is very - low, and as a result of the tight twisting of the bundle of wires any variation in the flux around the core is averaged out quite well. Also, since no current is flowing in the secondary winding of transformer " 0 " there are no errors due to unequal voltage drops in the various sections of the winding.

In tests made on a transformer wound in this manner the voltages between steps 0-4, and steps 5-9 agreed to within one part in 50,000,000 with no trimning, which is an improvement of more than a factor of ten over the prototype design, and for the same voltage output the impedance of the transformer is Iower. However, this transformer does have the disadvantage that its stray magnetic field is quite large, but this has been reduced to an insignificant level by inserting the completed transformer into a 5/16" wall, 5/16" bottom eluminum cup made by boring out the inside of a 3" O.D. x 4" long cylinder of $2014-F$ aluminum. This alloy has a very low resistivity, and therefore results in a very effective electromagnetic shield. The voltage balance between the windings was essentially unchanged after inserting the completed transformer into the shield cup, provided that $1 / 2$ " of clearance was allowed between the transformer and the inner bottom of the shield cup.

In the prototype bridge, transformer "I" was tuned to resonance and then connected directly between steps 4 and 5 of transformer "0", thereby loading this section and causing a voltage drop of approximately one part in 1,500,000 in the voltage between steps 4 and 5 . To offset this 10ading, the remaining sections of transformer " $O$ " vere also loaded by equivalent amoints. Also, in the prototype bridge, transformer " 2 " was 
twned to resonance with the required capacitance and was connected directly across adjacent taps on transformer " 1 ". To offset this Ioading effect two series strings of resistors were switched in such $a$ way that all sections of transformer " 1 " were equally loaded, independent of the switch position.

This loading problem has been solved in the present design by separately exciting the cores of transformers " 1 " and " 2 ". so that the voltage between the ends of their divider sections due to this excitation is equal to their working voltage, thus no loading of transformer " 0 " occurs when the divider section of transformer " $I$ " is connected between steps 4 and 5. Also, no loading occurs on any decade division of transformer " 1 " due to transformer "2".

The excitation windings on transformers " $I$ " and " 2 " are quite similar to the primary winding on transformer " 0 " (the main transformer). The excitation windings $A-A$ ' on core " 2 " and $B-B$ ' on core " 2 " are wound with two parallel strands of wire in a right hand direction around the core after first wrapping the core with $1-1 / 2$ mil mylar recording tape to prevent breaking through the wire insulation at the sharp edges of the core. After completely filling the inner circumference with this double pitch winding, one of the wires is removed and another wire is wound in a left hand direction, filling the altemate gaps on the inner circumference but overlapping the first wire on the outer circumference of the core. These two windings are then connected in series with the effect of canceling any stray PIux due to the current in the wires. This stray flux is important in cores " 1 " and "2" because these cores are not shielded and any stray flux would cause a voltage to be induced in any signal leads enclosing a significant area, especially the switch wixing for transformers " 1 " and "2" Which is very close to the cores. After completing the 
excitation windings for cores " 1 " and " 2 " the position of the individual turns was carefully adjusted to further reduce any external field by . inserting the excited core in a search coil and minimizing the observed emf for all orientations of the search coil, both in the plane of the core and perpendicular to it. The excitation wirding was then held in place with another wrapping of mylar tape. In this manner it was possible to reduce the external magnetic field to far below what would have been possible for a high permeability tape wound core, because of the effects due to the eddy currents and hysteresis loss in the laminations and the end effects due to the limited number of layers in metal tape cores (which begin and end abruptly, forming a discontinuity where the tape ends at both the inside and outside circumference of the core). This effect in metal tape cores is usually overcome by shielding the core, together with its primary or excitation winding, by a high permeability shield. This shield has the disadventage that it increases the size of the core and also reduces the window area available for winding.

For the final adjustment of transformer "I" the excitation windIng $A-A^{\prime}$ would be tuned to resonance with an appropriate parallel capacitor and the voltage across the winding would be varied by adjusting resistors $A$ and $A^{\circ}$ to obtain a sufficient flux in the core so that the total voltage across the ten section divider would be equal to the voltage across its ariving source (steps 4 to 5 of transformer "0"), and consequently when connected to the driver very littie current would flow in the ten section divider windings, since sufficient core flux 
will have been obtained from the excitation winding. The same procedure is used in the adjustment of transformer "2".

There are three main reasons for going to the trouble of separately exciting the divider cores in this manner. First, since no current is required from the previous divider there is no loading effect when the next divider stage is attached, and consequently very little voltage division error occurs from the effect of loading. (This minimization of loading could have been achieved equally well by simply: ignoring the separate excitation winding and separately driving the ends of the divider (tuned with the necessary capacitor) in the same manner that the excitation winding was driven, but this does not overcame a second effect. The second effect occurs because the cores are made of ferrite (having a relative permeability of $\approx 4,000$, which is quite low compared with high permeability metel tape cores), which when fully wound with copper wire has a maximum value of $\omega I / R$ (et $2 \mathrm{kHz}$ ) of approximately 5,000 for the cores which are presently used. Since it is desired to divide the voltage across transformer " $I$ " into ten parts all equal to within one part in a milion, it would be necessary to match the resistances of each of the ten wires used in the divider to better than one part in 200 to match the IR voltage drops in the ten wires to the required level. If it were this simple it would only be necessary to cut each wire to the same length and strip off equal amounts of insulation from the ends of the wires after carefully winding the ten wires to avoid stretching. Unfortunately, due to skin effect and proximity effect the voltage drop in the wires is not simply IR but IZ and this is quite dependent on the placement of the wires and how they are 
grouped together to form the bundle of ten. One method for minimizinE this effect is to randomly group the wires in a bundle making sure that no single strand is treated differently from any other strand, or alternatively the wires can be multiply tristed in multiple groups, or braided, or arranged in any manner that minimizes the large difference between the wires lying in the midale of the bundle from those on the outside of the bundle. This same procedure is used in Litzendraht ("Litz") wire to minimize skin and proximity effects, thus reducing the high frequency resistance of the wire. Independent of what method is used for the matching of the $Z$ in the various sections of the divider it is still important to minimize the current in order to minimize the overall result of the unbalance in $\mathrm{Z}$. The third advantage of separate excitation is the large reduction in the stray magnetic field which can be obtained because of the improved uniformity of the closely spaced excitation winding. This has the added advantage of preventing large variations in the leakage flux around the core and consequently the induced voltage in the divider section of the wound core is more uniform and less dependent upon the exact placement of the bundles of ten wires around the periphery of the core.

After completing the excitation windings on transformers " $I$ " and " 2 " it is still necessary to wind the ten section divider, and this is especially critical for transformer " 1 " since the resulting decade divider taps will be ajusted by "triming" to better then one part in $10,000,000$ of the voltage across transformer " 1 ". Several methods were attempted for winding this transformer, and the most promising method 
(which is also the most time consuming) requires the careful twisting of a group of ten equal length wires around a length of vinyl tubing having an outer diameter just sufficient to allow the ten wires to lie adjacent to one another in a well-defined single layer. Four groups of ten wires each, twisted around vinyl tubing in the above manner, are then carefully wrapped around core " 1 " in such a way that maximum winding uniformity and minimum enclosed area are obtained. By winding the cores in this manner there, is no difference between inner and outer wires in the bundle, since all of the wires are in one laver around the vinyl tubing. Also, since the wires axe uniforming spiraled around the tubing their neighbors remain the same from one end to the other, thus allowing the distributed capacitance to be minimized by suitably cornecting the wires.

Transformer " 2 " is wound in a much simplex manner. Three groups of wires, two groups having three wires each, and one group having four wires (a total of ten wires) are first twisted separately and then together to form a bunale of ten wires. Two of these bundles are then wound, one in a right hand direction, and one in a left hand direction, around core " 2 ". The resulting transformer has much less symmetry than transformer " 1 ", which results in a significantly larger variation between the voltages across the djvider. This method of winding is acceptable for transpormer " 2 " since it is only "trimmed" to $\sim$ one part in two million.

Transformers " 3 " and "4", which'are further down the divider string, are not as critical as the previous transformers and the separate 
excitation winding has been dispensed with. However, these transformers are still excited from windings on the isolation transformer to avoid excessive loading of the preceding transformer which would be dependent upon the switch position.

Transformer "4", although quite far down the divider, assumes importance for an entirely new reason. At this step in the divider string the transfomers change from being directly driven (reguiring two electrical connections or two switched contacts, independent of the means of excitation) to being coupled only through the magnetic field in the core of the transformer (requiring only one switched contact, and consequently simplifying the switching). At this point the high, although quite variable, relatively permeability of tape wound cores becomes a distinct advantage since it is possibie to achieve a larger value of $w / R$ than with ferrite cores, and therefore transformers " 4 " and " 5 " have supermalloy tape cores. The remaining trensformers, " 6 " and " 7 ", are sufficiently noncritical that they are wound with very few turns of thick wire on ferrite cores.

It might appear from the preceding description of the ratio transformer divider that the accuracy of the voltage division of the completed divider is the only consideration which must be taken into account. Unfortunately, most commercial ratio transformer dividers are designed to obtain only one major design objective, i.e., high voltage division accuracy for the real part of the voltage (the quadrature error in the resulting voltage division is of secondary importance). 
In a capacitance bridge used as a pressure gauge not only is it necessary to obtain high roltage division accuracy, but this high accuracy must be maintained even when the voltage divider section is Ioaded by the shunting effects of the coaxial cables and associated wiring which is necessary for connecting the capacitive pressure sensor and reference sensor to the capacitance bridge.

To achieve this immunity from the effects of loading requires that the effective output impedance of the divider be as low as possible consistent with the requirements for achieving high accuracy and high sensitivity to small changes in capacitance (which requires a reasonably large output voltage from the voltage divider). Each stage of the present voltage divider was consequently very carefully designed as an optimum compromise between the accuracy requirements and the equally important consideration of having as low an output impedance as possible. Commercial high accuracy decade divider transformers have such a large output impedence (which varies with the switch positions) that any loading at all is intolerable, while comercial high accuracy capacitance bridges bave neither the resolution nor the stability for the present use.

There is a winding on the isolation transformer which has not yet been mentioned. Since the capacitive samples used as the pressure sensor and the reference sensor will in general have a.small amount of loss, which will vary somewhat between samples, some provision must be made for balancing out the voltage at the detector resulting from the difference in the loss of the two samples. 
To achieve this loss balance a voltage is obtained from the isolation transformer which feeds a two-stage voltage divider. The first stage of this divider, which must provide signals of either polarity (hence the grounded center tap) is a ten-section transformer divider, while the second stage is a continuously variable potentiometer to obtain fine control of the loss balance roltage.

Most of the capacitive pressure sensors have a loss which is quite low, and therefore the high-low switch should usually be set at low. However, if the difference in the loss of the two samples is sufficientiy large it is necessary to chenge the loss switch to the high position. This provides in increase by a factor of ten in the allowable loss difference, but at the same time makes the setting of the fine loss control much more critical. Consequently, whenever possible the loss switch should be used in the low position.

A lossy capacitor corresponds to a lossless capacitor in paralleI with a resistance, and therefore the output of the loss divider must be coupled resistively to the input of the detector to cancel the unbalance due to this parallel resistance. It is undesirable to introduce this loss balance roltage directly through a resistor for two reasons. The large values of resistance which would be required are very unstable and are very poorly defined because of unavoidable shunt capacitances. Secondly, if the loss unbalance voltage were introduced directly through a resistor this resistor would be a significant source of thermal noise.

To minimize these two effects a resistor having a moderately high 
value is used and its resistance is effectively mutiplied by a capacitive divider consisting of two Corning glass capacitors having identical temperature coefficients. This arrangement, which requires an additional . RC network which must be trimmed to obtain the correct phase angle, overcomes both of the objections noted above. 


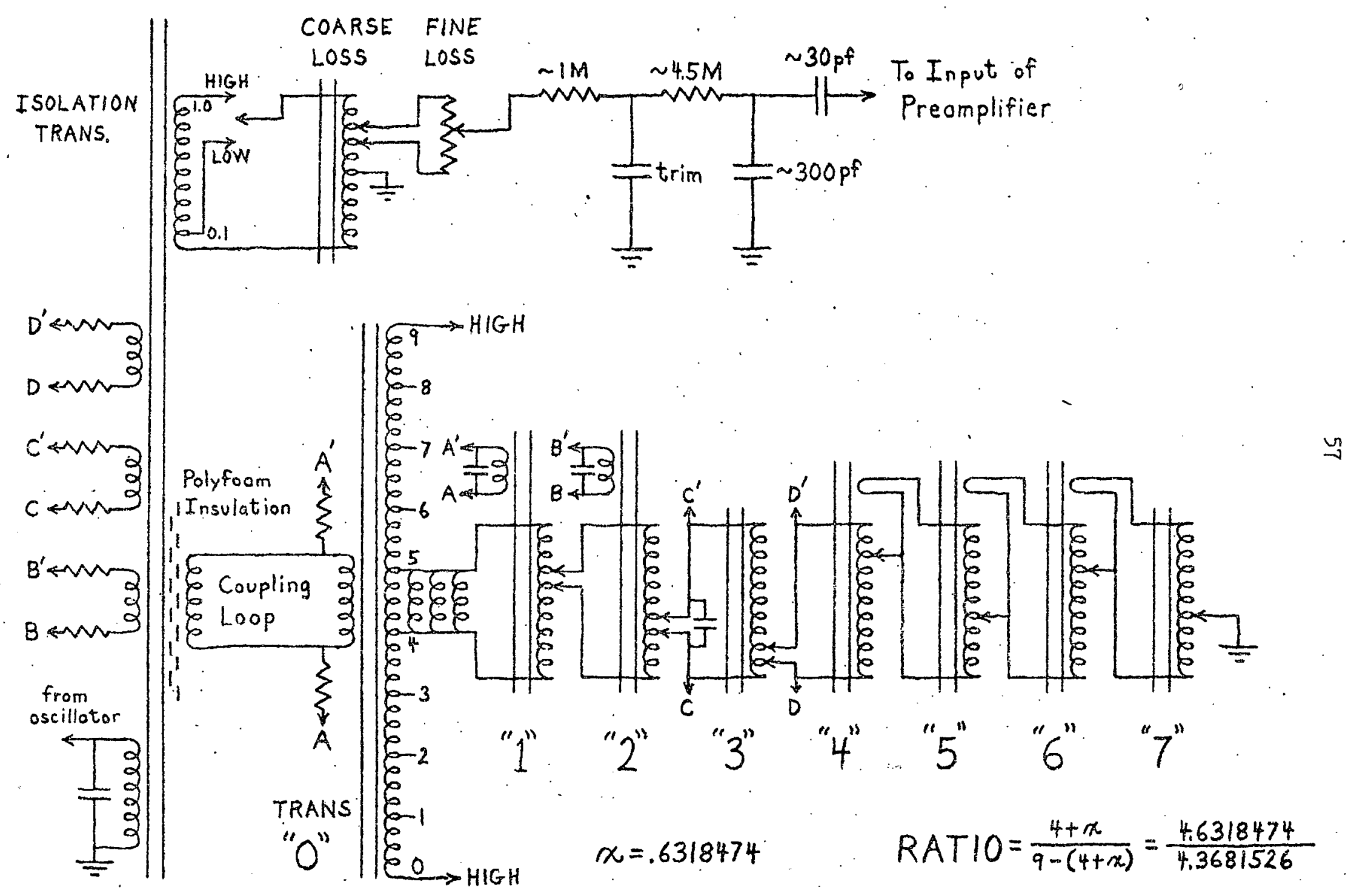

Schematic-3 Rotio and Loss Dividers for Copacitive Pressure Gauge 
Schematic 4 - Preamplifier and Tuned Amplifier

The prototype gauge used a high $Q$ inductor which was connected directly across its input terminals. This inductor was tuned to resonate in parallel with the cable capacitance and a variable capacitor, and at resonance resulted in a high input impedance (resistive in nature, and thus a source of thermal noise). Due to this high input impedence the voltage at the detector for a capacitive unbalance was rather large, and therefore an FET source follower, having a gain of $\sim 0.8$, was used to transform the high input impedance to directly drive a $709 \mathrm{C}$ operational amplifier. The noise from the input tuned circuit masked the noise from the FET and the $709 \mathrm{C}$, and hence the usable sensitivity of the circuit was determined almost exclusively by the tuned circuit at the input.

In the present circuit two low-noise FET amplifiers are cascaded to achieve a gain of $\sim 50$. Resistors $R_{1}$ and $R_{2}$, which are lownoise wirewound resistors, are adjusted to give a drain-source voltage of $\sim 7$ volts. The resulting nolse characteristics are quite superior to the prototype circuit and therefore the first $709 \mathrm{C}$ is selected for low noise so as not to deteriorate the otherwise excellent noise figure. Two stages of tuned amplification are used, with the tuned circuit being the same parallel resonant circuit that was used in the oscillator. Each tuned circuit is shunted to lower its $Q$ to 
$\sim 10$ to minimize phase shifts due to frequency variations. The gain of each stage of the tuned amplifier is adjusted by varying $R_{3}$ and $R_{4}$, and the output is boosted an additional factor of $\sim 20$ by an untuned amplifiex which minimizes coupling and nonlinearity effects due to the arect coupling into the lock-in detector, which had been a problem in the prototype circuit.

Since the voltage gain of this preamplifier-amplifier combination is greater than one million, the input and output circuits must be quite carefully shielded to avoid problems due to unwanted feedback. 


$$
\underbrace{\frac{\frac{2.8 \mathrm{H}}{\text { elebele }}}{\text { UTC MQE-15 }}}_{\text {T.C. }}=\underbrace{1}_{348 \mathrm{~K} 1 \%}
$$

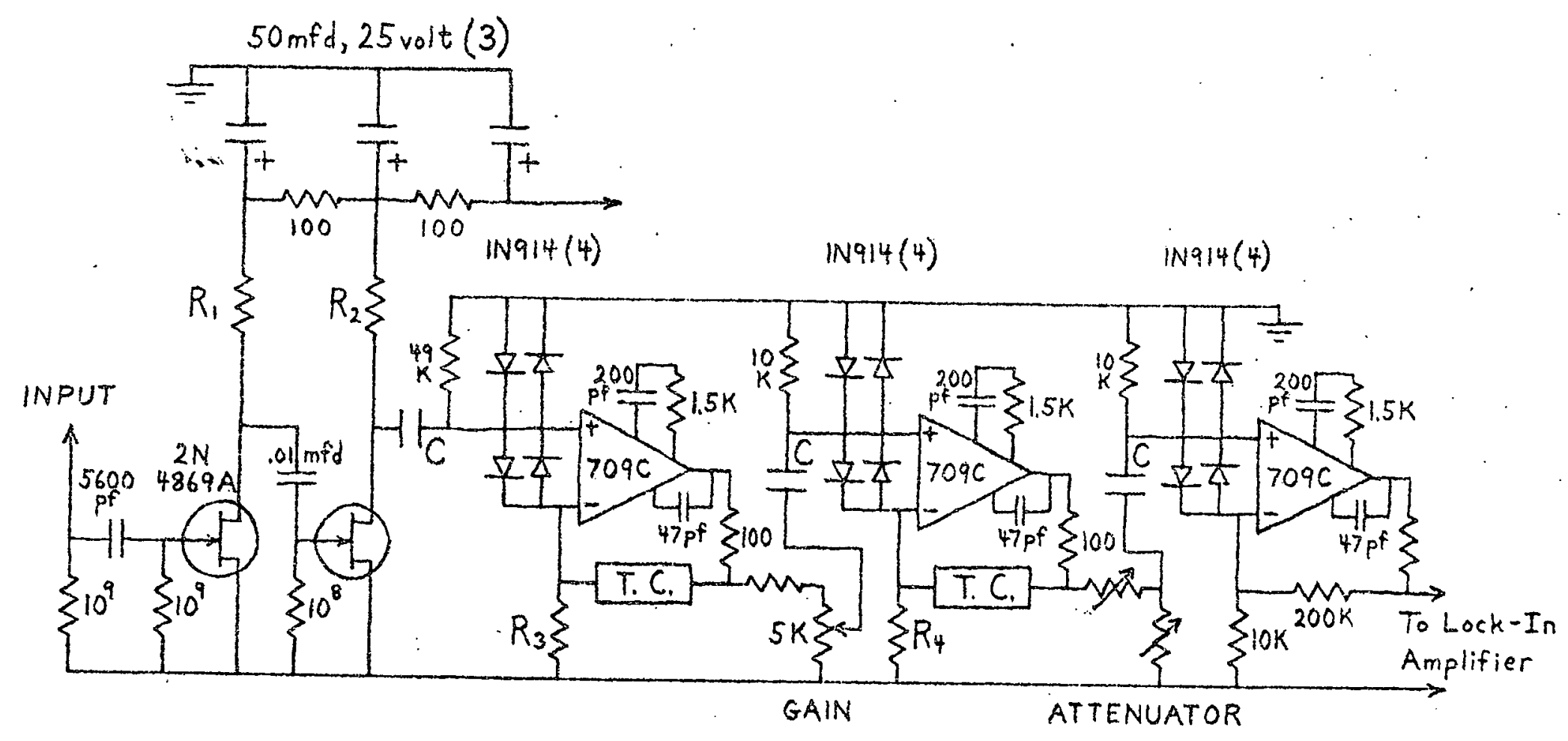

Schematic-4 Preamplifier and Amplifier for Copocitive Pressure Gauge 


\section{Schematic - 5 Dual Channel Lock-In Amplifier}

Since the lock-in amplifier which was used in the prototype gauge has performed so well it has been virtually unchanged in the present design. Two voltages, one in phase with the oscillator voltage, and one which is shifted in phase by $90^{\circ}$ in a dual RC network are individually sensed for the zero crossings of the resulting sine wave by the 709C. The output of this $709 \mathrm{C}$ is a square wave which rises and falls at the zero.crossing times of the sine wave, and this square wave output is used to drive a complementary push-pull demodulator circuit. The resulting output is $\mathrm{RC}$ filtered and yields $\mathrm{DC}$ voltages (both + and - ) which arive the differential amplifier at the output stage of each channel.

The balance meter for each channel is connected (In series with a $4.3 \mathrm{~K}$ resistor) between the emitters of the transistors in this output stage. The maximum DC voltage from the demodulator is limited by the 4-1N914 diodes in each channel, and this limits the maximum voltage difference between the electrolytic capacitors (thereby decreasing the time required to return to equilibrium after a large signal unbalance). The 2N3391's in the output stage limit the current in the balance meter to $\sim 10 \%$ beyond full scale on the meter (due to saturation of one $2 N 3391$ as the other turns off). The iN914's prevent the forward biasing of the bass-emitter junction which would conduct simply as a diode after sufficient saturation had occurred. . 
The resulting current limiting is very useful since the balance meter is linear on the calibrated portion of its scale, but the - maximum voltage at the output to a chart recorder is limited to $~ 10 \%$ more than the calibrated span. This prevents overdriving of the chart recorder, which can be a cause of motor burnout for some models if the pen is driven offscale and left unattended. 


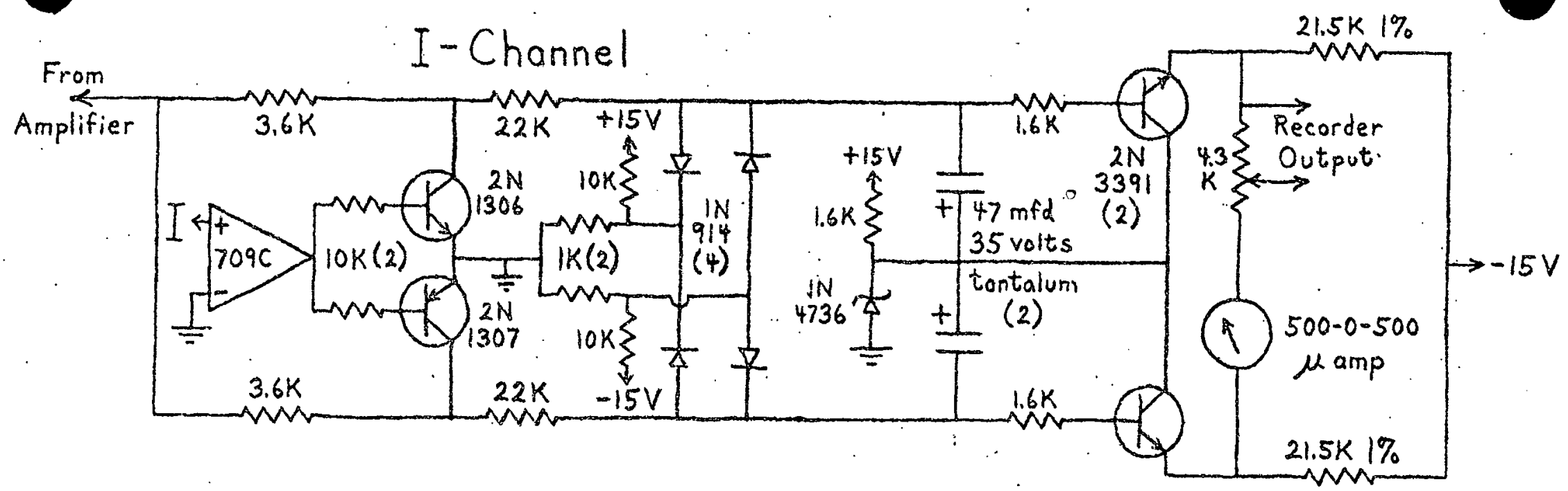

Q-Channel Identical Except for Omission of Recorder Output

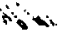

Phase Shifter

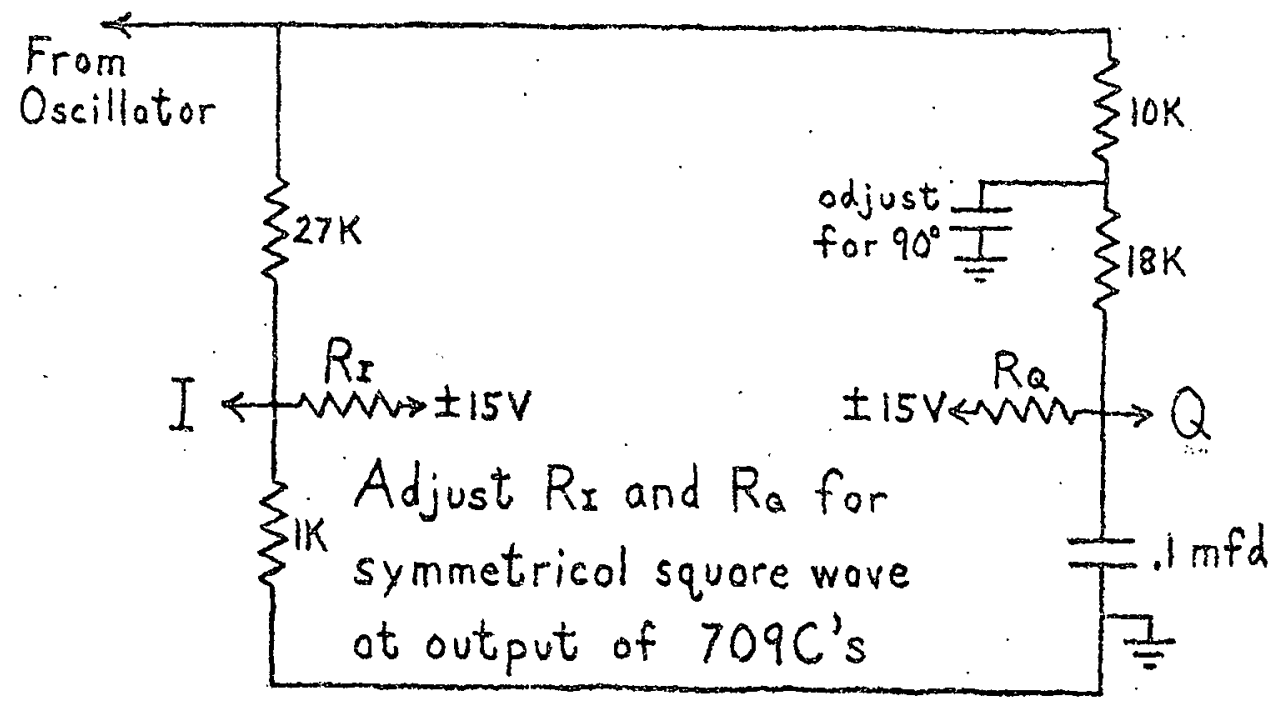

All resistors $1 / 4 W$ unless specified otherwise

Schematic-5 Duol Chonnel Lock-In Amplifier for Capocitive Pressure Gouge 
When one exsmines recent experimental results for the pressure coefficient of capacitance for insulating solids, and for $\mathrm{CaF}_{2}$ in particular, it would appear out of the question to even consider using this property as the basis of a highly accurate pressure gauge. As is pointed out in Reference 7 , recently published results for the pressure coefficient of capacitance for $\mathrm{CaF}_{2}$ differ by as much as 10-20\% from what is probably the correct value. However, as was indicated by the results obtained from the calibration performed at the National Bureau of Stindards, with sufficient attention to experimental detalls this property has become quite possibly the best measure of high pressures other than the dead weight piston gauge. The present report has dealt largely with changes which have been made in the prototype gauge setup to allow its use by those not so familiar with experimental techniques as was required for the original setup. The most significant changes (other than a complete redesign of the pressure vessel and electronics) have been the simplifications resulting from the immersion of the pressure vessel and attached reference capacitor enclosure into a controlled-temperature oil bath, and the removal of any tuning requirements while retaining or improving all of the feetures of the prototype design.

This report, together with AEC Tech. Rep. \#73, should make most of the mechanical details of the capacitive pressure gauge quite clear. However, the fact remains that the measurement of the pressure 
variation of the capacitance for $\mathrm{CaF}_{2}$ (or any other material) is not trivial or the inaccuracies in previously reported experimental results would not have occurred. Some of the intricacies of the sample chamber and reference chamber viring, as well as several subtleties associated with the capacitance bridge have not been covered in sufficient detail to allow duplication, and in some respects this has been intentional, since a minor detail which is ignored or glossed over could be a critical factor in the successful operation of the gauge. As mentioned previously, if a serious attempt is made to duplicate this capacitive high pressure gange, it would be desirable to contact the authors directly.

Present plans for development of this gauge center around a search for a better sensor material than $\mathrm{CaF}_{2}$, improvements in the deposition of the electrodes onto the sensors, further simplification of the apparatus, and an extension of the operating range to $200,000 \mathrm{psi}$, while hopefully retaining the high accuracy and ease of operation which have characterized the present setup. The results of these investigations will be reported as their. progress warrants. 
1. C. Andeen, J. Fontenella, and D. Schuele, AEC Tech. Rep. 68 $($ COO-623-155).

2. C. Andeen, J. Fontenella, and D. Schuele, Rev. Sci. Instru. 42 , 495 (1971).

3. C. G. Andeen, AEC Tech. Rep. 73 (C00-623-i69).

4. J. J. Fontanella, AEC Tech. Rep. 69 (CO0-623-165).

5. J. Fontanella, C. Andeen, end D. Schuele, Phys. Rev. B6, 582 (1972).

6. C. Andeen, J. Fontanella, and D. Schuele, AEC Tech. Rep. 75 $($ COO-623-180).

7. C. Andeen, J. Fontanella, and D. Schuele, Phys. Rev. B6, 591 (1972).

8. C. Andeen, J. Fontanella, and D. Schuele, AEC Tech. Rep. 78 $($ coo-623-182). 